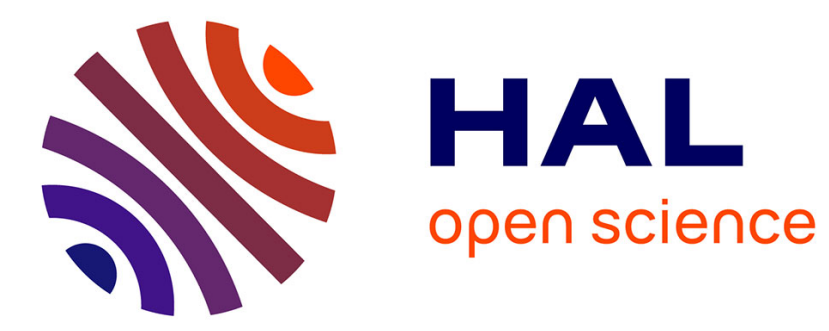

\title{
Optimization of multiroute synthesis for polyaniline-barium ferrite composites
}

Tayssir Ben Ghzaiel, Wadia Dhaoui, Alexander Pasko, Frédéric Mazaleyrat

\section{To cite this version:}

Tayssir Ben Ghzaiel, Wadia Dhaoui, Alexander Pasko, Frédéric Mazaleyrat. Optimization of multiroute synthesis for polyaniline-barium ferrite composites. Materials Chemistry and Physics, 2016, 10.1016/j.matchemphys.2016.05.008 . hal-01316638

\section{HAL Id: hal-01316638 \\ https://hal.science/hal-01316638}

Submitted on 17 May 2016

HAL is a multi-disciplinary open access archive for the deposit and dissemination of scientific research documents, whether they are published or not. The documents may come from teaching and research institutions in France or abroad, or from public or private research centers.
L'archive ouverte pluridisciplinaire HAL, est destinée au dépôt et à la diffusion de documents scientifiques de niveau recherche, publiés ou non, émanant des établissements d'enseignement et de recherche français ou étrangers, des laboratoires publics ou privés. 


\section{Optimization of Multiroute Synthesis for Polyaniline-Barium Ferrite Composites}

Tayssir BEN GHZAIEL ${ }^{\mathrm{a}, \mathrm{b}^{*}}$, Wadia DHAOUI ${ }^{\mathrm{a}}$, Alexander PASKO $^{\mathrm{b}}$, Frédéric MAZALEYRAT $^{\mathrm{b}}$

${ }^{a}$ Université de Tunis El Manar Faculté des Sciences de Tunis, UR11ES18 Unité de Recherche de Chimie Minérale Appliquée, 2092, Tunis, Tunisie

${ }^{\mathrm{b}}$ SATIE, ENS Cachan, CNRS, Université Paris-Saclay, 61 av du Président Wilson, F-94230 Cachan, France

*Corresponding author. Tel.: +33(0)1 $47402144^{\circ}$; e-mail address : tayssir.ben-ghzaiel@ satie.ens-cachan.fr

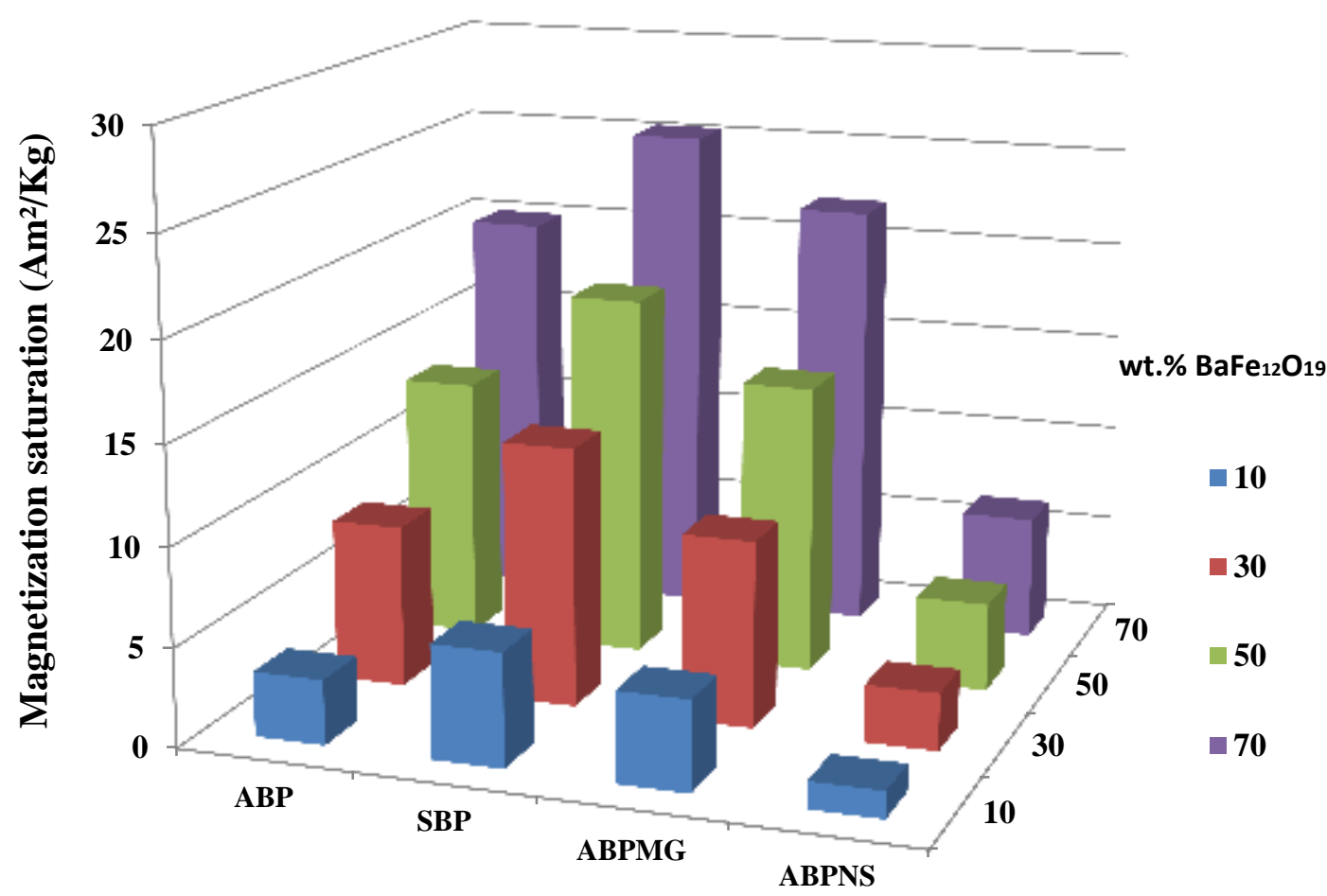

Synthesis Pathway

ABP : Aqueous-Based Polymerization

SBP : Solid-Based Polymerization

ABPNS : Aqueous -Based Polymerization Non Stirred

ABMG : Aqueous-Based Polymerization with Mechanical Grinding 


\section{ABSTRACT}

A comparative study of physicochemical and magnetic properties of Polyaniline- $\mathrm{BaFe}_{12} \mathrm{O}_{19}$ composites prepared by Solid-Based Polymerization (SBP) and by Aqueous-Based Polymerization $(\mathrm{ABP})$ is carried out. The composites obtained by the latter method underwent a grinding to study the influence of shear stress. Thus, in a systematic approach, an investigation of stirring effect was done by synthesizing these composites using aqueous-based polymerization but without mechanical stirring. Different mass ratio of $\mathrm{BaFe}_{12} \mathrm{O}_{19}$ was used to explore their impact on composites properties. X-ray diffraction, FTIR, SEM, TGA, conductivity and vibrating sample magnetometer measurements were performed. Structural and morphological investigations confirmed the presence of polyaniline and barium hexaferrite phase, which were in interaction in the composites regardless the polymerization route. The powder obtained by solid-based pathway revealed distinct particles with uniform distribution for various compositions (wt. \%) of $\mathrm{BaFe}_{12} \mathrm{O}_{19}$ in Pani, while the composites obtained by aqueous-based polymerization presented agglomerated nanostructures. Thermogravimetric analysis exhibited an improved thermal stability for Pani- $\mathrm{BaFe}_{12} \mathrm{O}_{19}$ obtained by solid-based route. The electric conductivity has displayed decreasing trend of $\mathrm{DC}$ conductivity with the increase of $\mathrm{BaFe}_{12} \mathrm{O}_{19}$ particles in the polymer matrix. Magnetic studies showed a ferromagnetic behaviour for all composites. The saturation magnetization monotonously increased with the increasing of $\mathrm{BaFe}_{12} \mathrm{O}_{19}$ amount. The magnetic properties of the powders were mainly related to the hexaferrite loading which was determined using measured magnetic data. These results revealed that magnetization saturation was dependant of volume fraction of ferrite in the composites which was significantly affected by the reaction medium and mechanical stirring. The powders obtained by solid-based polymerization manifested enhanced magnetic characteristics. The solventless reaction medium contributed to the increase of volume fraction of ferrite in the composite compared to the aqueous reaction medium. Moreover, the mechanical stirring during aqueous-based polymerization had an important influence on the volume fraction of ferrite since it prevented the dissolution of $\mathrm{BaFe}_{12} \mathrm{O}_{19}$ particles.

KEY WORDS: Composite materials; Chemical synthesis; Electrical conductivity; Magnetic properties;

\section{Introduction}

Hybrid materials, composed of both organic and inorganic units, offer wide opportunities for new materials with increased functionalities relative to that achievable with organic and inorganic materials alone [1-4]. Advances in composites consisting of conducting polymer have been widely investigated, 
specifically polyaniline (Pani) with various nanomaterials such as carbon nanomaterials, metal nanoparticles and inorganic compounds [5-12].

Over decades, numerous researches have been devoted to the study of polyaniline for its molecular structure, mechanism formation and different application as electronic-conducting polymer [13]. One of the particular features of Pani is the presence of intrinsic redox states. The term Pani usually denotes the family of aniline-based polymers of the following general formula $\left[(-\mathrm{B}-\mathrm{NH}-\mathrm{B}-\mathrm{NH}-)_{\mathrm{y}}(\mathrm{B}-\mathrm{N}=\mathrm{Q}=\mathrm{N}-)_{1-\mathrm{y}}\right]_{\mathrm{x}}$, in which $\mathrm{B}$ and $\mathrm{Q}$ denote respectively the $\mathrm{C}_{6} \mathrm{H}_{4}$ rings in the benzenoid and the quinoid rings.

In polyaniline the neutral intrinsic redox states can vary from that of the fully oxidized pemigraniline $(\mathrm{y}=0)$ to completely reduced leucoemeraldine $(\mathrm{y}=1)$, through the half-oxidized form, named emeraldine $(y=0.5)$ [14]. The emeraldine form of Pani can be doped with protonic acid to produce emeraldine salt (ES) [15].

One of the most prevalent types of these composites is composed of Pani and ferromagnetic barium hexaferrite $\left(\mathrm{BaFe}_{12} \mathrm{O}_{19}\right)$, with a general chemical formula $\mathrm{BaO}-6 \mathrm{Fe}_{2} \mathrm{O}_{3}$, used for potential application in antennas [16], radar absorbers [17, 18], tunable filters [19], electromagnetic shielding materials for low and high frequencies $[20] \ldots$

Several studies have focused on developing Polyaniline-barium hexaferrite composites to investigate their structural and electromagnetic properties. Nanocomposites of polyaniline charged with barium ferrite particles have been prepared using various methods. Pani- $\mathrm{BaFe}_{12} \mathrm{O}_{19}$ was synthesized by in situ chemical polymerization process with either mechanical stirring [21] or ultrasonic approach [22]. The nanocomposites showed a colloidal structure for potential microwave absorbers application. In addition, the emulsion polymerization method [23], with an easy and low cost preparation, was also used to fabricate conductive Polyaniline-ferrite composites. However, few papers have intended to study the effect of the elaboration method of these composites and their resultant physicochemical properties.

The present work aimed at synthesising Polyaniline- $\mathrm{BaFe}_{12} \mathrm{O}_{19}$ composites following different pathways: aqueous-based polymerization (acidic environment) and solid-based polymerization (solvent less environment). The impact of each preparation method and consequently the calculated ferriteloading using magnetic data on the magnetic properties and electrical conductivity was reported. The effect of mechanical stirring and shear stress caused by grinding on the formed nanocomposites and the following physicochemical properties was also discussed. 


\section{Experimental}

\subsection{Materials}

Aniline monomer (Ani, analytical grade, Merck) was distilled twice under reduced pressure and stored in the refrigerator. Iron (III) nitrate nonahydrate $\mathrm{Fe}\left(\mathrm{NO}_{3}\right)_{3}, 9 \mathrm{H}_{2} \mathrm{O}$, barium nitrate $\mathrm{Ba}\left(\mathrm{NO}_{3}\right)_{2}$, sodium hydroxide $(\mathrm{NaOH})$, aniline chloride $(\mathrm{AnCl})$, ammonium persulfate $\left(\left(\mathrm{NH}_{4}\right)_{2} \mathrm{~S}_{2} \mathrm{O}_{8}, \mathrm{APS}\right)$ and hydrochloric acid $(\mathrm{HCl})$ were all of analytical purity purchased from commercial sources, and used directly without further purification.

\subsection{Synthesis of $\mathrm{BaFe}_{12} \mathrm{O}_{19}$ particules $(\mathrm{HF})$}

$\mathrm{BaFe}_{12} \mathrm{O}_{19}$ powder was prepared by the hydrothermal process using an autoclave introduced into a shaked furnace. A mixture of $\mathrm{Fe}\left(\mathrm{NO}_{3}\right)_{3}, 9 \mathrm{H}_{2} \mathrm{O}$ and $\mathrm{Ba}\left(\mathrm{NO}_{3}\right)_{2}$ were added to 2.5 mol. $\mathrm{L}^{-1} \mathrm{NaOH}$ solution according to desired stoichiometries. The mixture was then poured into the autoclave and heated at $220^{\circ} \mathrm{C}$ during $8 \mathrm{~h}$. The resulting powder was repeatedly washed with distilled water and dried at $80^{\circ} \mathrm{C}$. Then, it was calcined at $900^{\circ} \mathrm{C}$ for $2 \mathrm{~h}$ inside a muffle furnace.

\subsection{Synthesis of Polyaniline-BaFe ${ }_{12} \mathrm{O}_{19}$ composites by Solid-Based Polymerization (SBP)}

Polyaniline- $\mathrm{BaFe}_{12} \mathrm{O}_{19}$ composites were obtained by Solid-Based Polymerization (Fig. 1 a) as follows: the synthesis was carried out in an agate mortar by grinding an appropriate amount of $\mathrm{An}-\mathrm{Cl}$ and $\mathrm{BaFe}_{12} \mathrm{O}_{19}$ for $10 \mathrm{~min}$. Then APS was added to the mixture and ground for $20 \mathrm{~min}$ until the colour turned dark green. Different mass ratios of $\mathrm{BaFe}_{12} \mathrm{O}_{19}$ were used: 10, 30, 50, and 70 wt. \% with respect to aniline monomer and the samples were marked as 10SBP, 30SBP, 50SBP and 70SBP, respectively. The polymerization lasted for $24 \mathrm{~h}$ at room temperature. The dark green product was filtered, washed by $\mathrm{HCl}(0.2 \mathrm{M})$ until the filtrate became colourless then dried in vacuum at $60^{\circ} \mathrm{C}$ for $24 \mathrm{~h}$. Throughout the experiment the molar ration of aniline to APS was maintained at 1.25.

\subsection{Synthesis of Polyaniline-BaFe ${ }_{12} \mathrm{O}_{19}$ composites by Aquous-Based Polymerization (ABP)}

Likewise, Polyaniline- $\mathrm{BaFe}_{12} \mathrm{O}_{19}$ composites were prepared by Aqueous-Based Polymerization of aniline in the presence of $\mathrm{BaFe}_{12} \mathrm{O}_{19}$ particles using APS as oxidant, as shown in Fig. 1 b. In a typical procedure, a certain amount of $\mathrm{BaFe}_{12} \mathrm{O}_{19}$ particles was added to $0.2 \mathrm{M}$ aqueous solution of hydrochloric acid containing aniline monomer sonicated in an ultrasonic bath for $30 \mathrm{~min}$. Then, $5.71 \mathrm{~g}$ APS dissolved in $0.2 \mathrm{M} \mathrm{HCl}$ solution was then added to the above mixture under mechanical agitation. The polymerization was carried out with the same barium hexaferrite and reagent ratios as above for $24 \mathrm{~h}$ at room temperature. The products were isolated by filtration, thoroughly washed with $\mathrm{HCl}$ for removal of 
inorganic residues, then dried in vacuum at $60^{\circ} \mathrm{C}$ for $24 \mathrm{~h}$. The composites were called as $10 \mathrm{ABP}$, $30 \mathrm{ABP}, 50 \mathrm{ABP}$ and 70ABP, respectively.

For further investigation, mechanical stirring was studied by preparing Pani- $\mathrm{BaFe}_{12} \mathrm{O}_{19}$ composites following the same procedure as described before in aqueous-based polymerization, but without mechanical agitation called ABPNS (Aqueous-Based Polymerization Non Stirred). The samples ratios of $\mathrm{BaFe}_{12} \mathrm{O}_{19}$ in weight (wt. \%) were identical: 10 (10ABPNS), 30 (30ABPNS), 50 (50ABPNS) and 70 (70ABPNS), respectively.

In addition, to examine the effect of shear stress caused by grinding during solid-based polymerization on Pani- $\mathrm{BaFe}_{12} \mathrm{O}_{19}$ composites, we prepared Polyaniline- $\mathrm{BaFe}_{12} \mathrm{O}_{19}$ samples by $\mathrm{ABP}$ route which were treated by a post-synthesis grinding in the agate mortar for 20 minutes. This treatment is designated as ABPMG (Aqueous-Based Polymerization with Mechanical Grinding) and the samples were named: 10ABPMG, 30ABPMG, 50ABPMG and 70ABPMG.

For comparative purpose, pure polyaniline doped with $\mathrm{HCl}$ was also synthesized under similar conditions as above. The codes assigned to the prepared composites are shown in Table 1.

\subsection{Characterization}

X-Ray Diffraction (XRD) patterns were recorded on PANalytical X'Pert Pro diffractometer using Cobalt $\mathrm{K}_{\alpha}$ radiation $(\lambda=1.79 \AA)$ in the range of $2 \theta=10-80^{\circ}$ with $0.002^{\circ}$ increment. All the X-ray diffraction patterns were analysed with the MAUD programme by employing Rietveld refinement technique. Scanning Electron Microscopy (SEM) images were taken on a Hitachi S-3400N scanning electron microscope. Fourier Transform Infrared (FTIR) spectra were collected on a Thermo Electron Corporation Nicolet Nexus 670 FT-IR Spectrometer using pressed KBr pellets. The FTIR spectra were recorded with a resolution of $1 \mathrm{~cm}^{-1}$ over the range of $4000-400 \mathrm{~cm}^{-1}$. Thermal analysis of the samples was carried out by using Perkin Elmer Pyris 6 TGA analyser with a heating rate $10^{\circ} \mathrm{C} \cdot \mathrm{min}^{-1}$ in nitrogen atmosphere. The conductivity of Pani composites pellets was measured at room temperature by using a standard four-probe method using a Keithley 2636 A Dual-channel System Source Meter Instrument with 6-1/2 digit System DMM which combined a power supply and true current source. Magnetic properties of the composites were measured at room temperature on vibrating sample magnetometer VSM Lake Shore 7400 model. 


\section{Results and discussion}

\subsection{Structure, composition and morphology}

Fig. 2 and 3 show the XRD spectra of the $\mathrm{BaFe}_{12} \mathrm{O}_{19}$ and Pani- $\mathrm{BaFe}_{12} \mathrm{O}_{19}$ powders. Fig. 2 shows the presence of very well defined Bragg peaks indicating a good crystalline state of barium hexaferrite. Rietveld refinement on the X-ray powder diffraction patterns using MAUD program is performed [24]. Crystal cell parameters and phase fractions are determined (Fig. 2). These refinements confirm the presence of a well-formed single phase of $\mathrm{BaFe}_{12} \mathrm{O}_{19}$ with an hexagonal structure ( $\mathrm{P} 63 / \mathrm{mmc}$ space group) [25]. The observed diffraction peaks can be indexed as (101), (102), (110), (008), (107), (114), (203), (205), (206), (217), (2011), and (220) planes of the hexagonal magnetoplumbite structure (JCPDS cards 74-1121).

As seen in Fig. 3 a, b, c, and d, diffraction peaks position and intensity of the Polyaniline- $\mathrm{BaFe}_{12} \mathrm{O}_{19}$ composites synthesized by ABP, SBP, ABPNS and ABPMG ways are similar to those of pure barium hexaferrite. The crystal phase of magnetic particles seems to be well maintained after the synthetic process, based on the fact that there is no change in peak position between $\mathrm{BaFe}_{12} \mathrm{O}_{19}$ and the composites. In addition, there is a wide peak in the range of $2 \theta=20-30^{\circ}$ which is attributed to the diffraction peak of Pani and proves the existence of the polymer [26]. Expectedly, this peak decreases with increasing the amount of hexaferrite in the polymer.

The calculated values of lattice parameters, unit cell volume and crystallite size for $\mathrm{BaFe}_{12} \mathrm{O}_{19}, 50 \mathrm{ABP}$, 50SBP, 50ABPMG and 50ABPNS samples are listed in Table 2. The grain size of pure barium ferrite is found about $134 \mathrm{~nm}$ with calculated cell parameters $\mathrm{a}=0.589 \mathrm{~nm}, \mathrm{c}=2.32 \mathrm{~nm}$ and unit cell volume of $0.697 \mathrm{~nm}^{3}$ which are in good agreement with the published data [27]. For composites prepared by solidbased polymerization, the lattice constants, unit cell volume and the crystallite size of $\mathrm{BaFe}_{12} \mathrm{O}_{19}$ do not change. Meanwhile, the crystallite size decreases in the case of the composites obtained by the other pathways. Under identical synthesis conditions, 50ABP and 50ABPMG presented the same magnetic particle size. This value is slightly lower than that the pure ferrite. It can be related to the presence of acidic environment required for polyaniline synthesis. In the case of sample 50 ABPNS an increase in unit cell volume is observed from 0.697 to $0.700 \mathrm{~nm}^{3}$ for $\mathrm{BaFe}_{12} \mathrm{O}_{19}$. It may be due to the diffusion of hydrochloric acid proton in $\mathrm{BaFe}_{12} \mathrm{O}_{19}$ lattice. As seen in Table 2, magnetic particles in 50ABPNS composites have lost $30 \%$ of their initial crystallite size. This marked size decrease indicates that these particles underwent acidic dissolution mechanism during the formation of the nanocomposite. In contrast, under the same acidic medium, mechanical stirring seem to have an effect on the ferrite 
crystallite size. This latter does not show an important size reduction, which confirms that the agitation can decrease the dissolution effect caused by acidic environment. (These observations will be more developed in magnetic section).

Additional analysis of the crystalline transitions and interactions between polyaniline and barium ferrite in the composites is performed using FTIR spectroscopy. The aim is to obtain an improved understanding of the physicochemical interactions between ferrite particles and polyaniline during the polymerization process. FTIR spectra are recorded from $4000-400 \mathrm{~cm}^{-1}$ for the different samples, however, figures show only expanded view in wavenumber region $400-2000 \mathrm{~cm}^{-1}$, where major changes are observed as shown in Fig. 4 and 5. The FTIR spectrum of the hydrothermally prepared $\mathrm{BaFe}_{12} \mathrm{O}_{19}$ shows absorption band at $578 \mathrm{~cm}^{-1}$ and $430 \mathrm{~cm}^{-1}$ (Fig. 4 a) related to the intrinsic vibrations of tetrahedral and octahedral sites of Fe-O for hexaferrite, respectively [28, 29]. There are no peaks in the range 800 to $2000 \mathrm{~cm}^{-1}$, indicating the absence of any hydroxides or hydrated oxides of iron and barium [30].

Fig. $4 \mathrm{~b}$ and Fig. $5 \mathrm{a}, \mathrm{b}$, c and d show the FTIR spectra of pure Pani and Polyaniline- $\mathrm{BaFe}_{12} \mathrm{O}_{19}$ composites obtained by ABP, SBP, ABPNS and ABPMG syntheses, separately. Characteristic peaks of polyaniline are observed in all the samples, indicating the formation of Pani emeraldine salt [31].

The main characteristic peaks of the ABP composites are assigned as follows:

The band at $1569 \mathrm{~cm}^{-1}$ can be associated mainly to the characteristic $\mathrm{C}=\mathrm{N}$ stretching vibration of quinoid diimine unit $\mathrm{N}=\mathrm{Q}=\mathrm{N}$, while the band near $1491 \mathrm{~cm}^{-1}$ is assigned to the $\mathrm{C}-\mathrm{C}$ aromatic ring stretching of benzenoid diamine unit N-B-N. The main bands at 1302 and $1245 \mathrm{~cm}^{-1}$ correspond to $\pi$-electron delocalization induced in the polymer through protonation or asymmetric $\mathrm{C}-\mathrm{N}-\mathrm{C}$ stretching modes of benzenoid and $\mathrm{C}-\mathrm{N}^{+}$stretching vibration of the Polaron structure, respectively [32]. The wide band around $1142 \mathrm{~cm}^{-1}$ which is called conduction band, is attributed to the vibration mode of $\mathrm{B}-\mathrm{NH}^{+}=\mathrm{Q}$ or $\mathrm{B}-\mathrm{NH}^{+}-\mathrm{B}$ in the protoned emeraldine base form [33]. It refers to a clear delocalization of electrons in Pani [34]. The absorption band at $815 \mathrm{~cm}^{-1}$ corresponds to $\mathrm{C}-\mathrm{H}$ out of plane vibration of the pdisubstituted benzene ring.

In the case of composites obtained by solid route, the main absorption peaks observed for aqueous way at $1569,1491,1302,1245,1142$ and $815 \mathrm{~cm}^{-1}$ and assigned above are red shifted to 1567, 1488, 1297, $1243,1127,810 \mathrm{~cm}^{-1}$ (Fig. 5 b). This shift can be due to the difference of oxidation and/or protonation levels [35] according to the synthesis pathway. The relative oxidation level (Q/B) may be estimated from the ratio of quinoid and benzenoid band intensities [36]. These ratios are 0.84 and 0.78 for ABP and SBP samples, respectively. ABP composites show the highest oxidation ratio, which indicates the 
presence of more emeraldine salt form. These results are mainly related to the oxidant and amount of $\mathrm{H}^{+}$ in the medium [37]. Since solid-based polymerization is a solventless method, the probability of contact between oxidant and monomer is low. So, there is formation of more polyaniline reduced form [38]. The presence of $\mathrm{H}^{+}$in aqueous-based polymerization promote the reaction between aniline and APS and allows the formation of polyaniline oxidized form [39] which is confirmed by the prepared ABPNS composites with an oxidation level of 0.88 .

For ABPMG samples, it seems that shear stress induced by grinding has an impact. Indeed, the absorption peaks observed for ABP at 1302, 1245, 1132, and $815 \mathrm{~cm}^{-1}$ are shifted to $1299,1243,1127$ and $812 \mathrm{~cm}^{-1}$ (Fig. $5 \mathrm{f}$ ). This may be attributed to an increase of the interaction between ferrite particles and Pani due to grinding treatment.

For Polyaniline-ferrite composite samples obtained by ABP, SBP and ABPMG, two bands related to stretching vibration of $\mathrm{Fe}-\mathrm{O}$ are observed at 574 and $424 \mathrm{~cm}^{-1}$ indicating the existence of hexaferrite in the polymer matrix. These absorption bands, appearing at a noticeable red shift compared to pure hexaferrite, decrease clearly with the decrease of hexaferrite weight percentage in the composite $[40,41]$. The FTIR spectra of Pani- $\mathrm{BaFe}_{12} \mathrm{O}_{19}$ composites for different ratios prepared by aqueousbased polymerization without stirring are characterized by the reduction or even disappearance of the characteristic IR bands of iron-oxide vibrations of barium hexaferrite as shown in Fig. $5 \mathrm{~d}$ is confirming the dissolution of $\mathrm{BaFe}_{12} \mathrm{O}_{19}$ particles during the polymerization as was examined by XRD.

Scanning electron microscopy is used to examine the morphology of the prepared barium hexaferrite particles and Polyaniline- $\mathrm{BaFe}_{12} \mathrm{O}_{19}$ composites with 10 and 50 wt. \% ratios obtained by different pathways (Fig. 6, 7 and 8). As seen in Fig. 6, $\mathrm{BaFe}_{12} \mathrm{O}_{19}$ particles obtained by hydrothermal synthesis exhibit a hexagonal platelet-like shape and an average size of $340 \mathrm{~nm}$. Agglomeration appears due to interactions between magnetic particles.

Fig.7 and 8 show Polyaniline- $\mathrm{BaFe}_{12} \mathrm{O}_{19}$ composites prepared by different syntheses with low and high weight fraction of ferrite, respectively. It is well viewed that the morphology and the size of the composites are influenced by the ferrite weight ratio and the synthesis pathway. As seen in Fig. 7 a, when 10ABP composites are obtained, agglomerations are formed. Closer inspection of the image clearly reveals agglomerated spherically-shaped Pani nanostructures where barium ferrite particles are encapsulated in the Polymer matrix. With the incorporation of more hexaferrite nanoparticles (50 wt. $\%)$, the nanocomposite appears as an agglomeration of platelet-like structures (Fig. 7 b). This result 
may be due to the presence of a high concentration of $\mathrm{BaFe}_{12} \mathrm{O}_{19}$ nanoparticles, which afford a highly compact morphology.

The morphologies of the nanocomposites produced by solid-based polymerization for 10 and $50 \mathrm{wt}$ \% $\%$ ratios of hexaferrite are shown in Fig. $7 \mathrm{c}$ and d. Note that the morphology of the composite reveals short rod-like structures for $10 \mathrm{SBP}$ sample (Fig.7 c). As the content of $\mathrm{BaFe}_{12} \mathrm{O}_{19}$ increases, a remarkable change in morphology is observed; the 50 SBP nanocomposites (Fig.7 d) appeared as a well dispersed hexagonal platelet like structures with an average size of $1 \pm 0.1 \mu \mathrm{m}$. These changes in morphology can be related to the reaction medium of the formed nanocomposites. In fact, unlike solventless medium, in aqueous medium, there is more contact between the monomer, oxidant and ferrite particles [42]. In $\mathrm{HCl}$ solution, aniline monomer can form easily anilinium ions, while, chloride ions can compensate the positive charges on $\mathrm{BaFe}_{12} \mathrm{O}_{19}$ surface, as a result electrostatic forces are created between anions adsorbed at ferrite surface and anilinium ions [43]. These electrostatic interactions favour the aggregation of Pani- $\mathrm{BaFe}_{12} \mathrm{O}_{19}$ nanocomposites [44].

Moreover, it is worth noting that the resulting Pani composite forms are not only influenced by reaction medium, but also by mean of mechanical agitation during polymerization. Actually, the stirring affects the composite morphology since it protected ferrite particles from dissolution by acid attack, as shown in ABPNS samples with inhomogeneous morphology and random distribution compared to $\mathrm{ABP}$ samples (Fig. 8 a and b).

In Fig. 8 c, and d, for 10 wt. \% and 50 wt. \% content of ferrite, the composites obtained by ABP route treated by a post-synthesis grinding present spherical-like morphology. It can be deduced that the grinding treatment may reduce particle size and allow a uniform dispersion of the particles [45].

The above results will affect the conductivity and magnetization of the samples, as it will be discussed later.

In order to determine the weight loss due to the loss of moisture and decomposition of the polymer, thermogravimetric analysis is carried out for Pani- $\mathrm{BaFe}_{12} \mathrm{O}_{19}$ composites with 10 and 50 wt. \% ratios of hexaferrite obtained by different syntheses in a nitrogen atmosphere. Fig. 9 displays the thermograms of these composites. All the samples present three major weight losses. The first weight loss just below $100^{\circ} \mathrm{C}$ is due to the evaporation of moisture in the composites [46]. The second weight loss in the range of $160-380^{\circ} \mathrm{C}$ may be attributed to the removal of the dopant anions bound to the polymer chain and degradation of oligomers. The slow and gradual third major loss above $430^{\circ} \mathrm{C}$ is attributed to the complete decomposition of the Pani backbone in the composites [47]. As expected, $\mathrm{Pani}-\mathrm{BaFe}_{12} \mathrm{O}_{19}$ 
composite with $50 \mathrm{wt}$. $\%$ of ferrite have greater thermal stability than that composites with $10 \mathrm{wt}$. $\%$ for the same synthesis method. Increasing stability of polyaniline composites with the increasing hexaferrite content can be explained by the presence of a strong interaction between ferrite particles and Pani matrix, improving the thermal degradation of this latter in the composites [48].

Thermal degradation temperatures and the corresponding weight loss percentage for each composite are given in Table 3. The thermal degradation temperatures of 10ABP, 10SBP, 50ABP and 50SBP composites are $489,517,519$ and $532^{\circ} \mathrm{C}$, respectively. These results reveal that composites obtained by solid-based polymerization exhibit higher thermal stability than that of composites obtained by aqueous-based polymerization. It can be attributed to their lower oxidation level and doping degree, as confirmed FTIR analysis [43]. This latter may be calculated [49] using the obtained results from Fig. 9 and Table 3. It is estimated about 94, 78, 89.2 and $69 \%$ for 10ABP, 10SBP, 50ABP and 50SBP, respectively. Hence, composites prepared by aqueous route have a greater doping level than that by solid route.

Moreover, ABPMG composites are more stable than ABP composite. Their temperature decomposition increases from 489 to $510^{\circ} \mathrm{C}$ and 519 to $522^{\circ} \mathrm{C}$ for $10 \mathrm{wt}$. \% and $50 \mathrm{wt} \%$ of magnetic particles, respectively (Table 3). This increase is believed to be due to the applied shear stress by grinding. Apparently, grinding treatment enhances thermal stability of the composites. Otherwise, ABPNS composites show lower thermal stability than that of ABP composites, and there is $23.8 \%$ and $21.7 \%$ reduction in mass loss for 10ABPNS and 50ABPNS, respectively. This phenomenon may be a result of a partial attack of ferrite particles by means of $\mathrm{HCl}$ used as a dopant for polyaniline in the synthesis process which can be minimised by mechanical stirring for ABP samples.

\subsection{DC conductivity}

To study the effect of the synthesis method on electrical conductivity in the obtained composites, the resistivity of the samples is measured by the four-probe method at room temperature. Powders of the composites are compacted into pellets in thickness of $0.7 \mathrm{~mm}$ with $8 \mathrm{~mm}$ diameter at the same pressure. The resistivity $\rho$ and DC conductivity $\sigma_{\mathrm{dc}}$ of the nanocomposites pellets can be given by [50]:

$$
\begin{array}{r}
\rho=\frac{\mathrm{V}}{\mathrm{I}} \frac{\pi}{\ln 2} e \\
\sigma_{\mathrm{dc}}=\frac{1}{\rho}
\end{array}
$$


where $(\pi / \ln 2)$ is a constant, $\mathrm{V}$ the applied voltage to the sample, I the measured current and e is the thickness of the nanocomposite pellet.

The DC conductivity values are presented in Fig. 10. Synthesised composites are considerably conductive. Values of $\sigma_{\mathrm{dc}}$ decrease with the increasing $\mathrm{BaFe}_{12} \mathrm{O}_{19}$ amount in the composites for all syntheses meanwhile the samples obtained by ABP show greater conductivity compared to those synthesised by SBP method. Their maximum $\sigma_{\mathrm{dc}}$ value is $1.310^{-3} \mathrm{~S} . \mathrm{cm}^{-1}$ for $10 \mathrm{wt}$. \% ratio of barium hexaferrite at room temperature. This notable conductivity can be explained by a greater oxidation level and doping degree. As found from the FTIR spectra, oxidation level is about 0.84 and 0.78 for ABP and SBP composites, respectively. In fact, the increase of oxidation leads to more formation of emeraldine salt form in the polymer which plays an important role towards the achievement of high conductivity [51]. For aqueous-based polymerization the fact that the reaction takes place in solution provides a more effective channel for the movement of charges than solid-based polymerization, so the charge carrier can hop along the polymeric chain, from one layer to another or among particles in the composites [52]. In addition, the percentage of doping level is a significant factor to obtain a high conductivity. The protonation of Pani leads to the formation of Polaron structure where the conduction occurs by hopping [53]. Solid-based method showed the lower doping percentage than aqueous-based route, determined using thermogravimetric analysis. Moreover, these samples presented a lower oxidation level, which caused the protonation of partial quinoid rings. This would cause the formation of few polarons leading to a low conductivity. The mechanical grinding has a considerable effect on the conductivity of polyaniline composites. In Fig. 10, the conductivity of the ABP composites treated with a mechanical grinding for $20 \mathrm{~min}$ decreases. It is attributed to the mechanical shear stress induced by grinding which would shorten conjugation lengths of the polymeric chains in the composites and as a result a decrease in the conductivity [54].

Furthermore, the stirring effect has a significant influence on the composite preparation. As seen in Fig. 10, ABPNS particles present lower $\sigma_{\mathrm{dc}}$ which indicates that the mechanical stirring may improve the resistance of particles from dissolution by protons arising from Pani matrix coating the hexaferrite particles [55]. During composites formation under the unstirred process, ferrite particles can react at its interface with the acid when the polymerization occurred. The interaction of ferrite particles with hydrochloric acid takes place by the diffusion of protons throw barium ferrite external layer. Mechanical agitation can minimize this diffusion to protect the nanoparticles from dissolution. 


\subsection{Magnetic properties}

The M-H curves of barium hexaferrite and the composites with initial weight percentage of 10, 30, 50 and $70 \mathrm{wt}$. \% of ferrite (or as called theoretical weight fraction) for the different synthesises methods at room temperature, are presented in Fig. 11 and 12. The magnetization under applied magnetic field, for the as-prepared samples, exhibits clear hysteresis loops, indicating the ferromagnetic nature.

The magnetic parameters, namely, the saturation magnetization $\left(\mathrm{M}_{\mathrm{s}}\right)$ the remanent magnetization $\left(\mathrm{M}_{\mathrm{r}}\right)$ and the coercivity $\left(\mathrm{H}_{\mathrm{c}}\right)$ as obtained from the curves in Fig. 11 and 12 are summarized in Table 4. $\mathrm{M}_{\mathrm{s}}$ of the material is defined as the maximum induced magnetic moment measured in a sufficiently large magnetic field, beyond this field no further increase in magnetization occurs. $M_{r}$ is the ability of a material to hold magnetism after the applied magnetic field was removed. And $\mathrm{H}_{\mathrm{c}}$ is the intensity of the applied magnetic field to a sample required to reduce the magnetization from saturation to zero. These parameters are not only intrinsic properties, but also dependent on particle size, domain state, stresses and temperature [56].

As listed in Table 4, saturation magnetization of hydrothermally synthesized barium hexaferrite is 66.65 $\mathrm{Am}^{2} / \mathrm{Kg}$ at room temperature, which is close to the theoretical one calculated for single-crystal barium hexaferrite, $72 \mathrm{Am}^{2} / \mathrm{Kg}$, as reported by Shirk and Buessem [57]. In addition, the intrinsic coercivity is about $0.1118 \mathrm{~T}$, which is similar to most of the hydrothermally synthesized barium hexaferrite reported earlier [58], related to the enhancement in crystallinity of hydrothermally synthesised $\mathrm{BaFe}_{12} \mathrm{O}_{19}$ particles as confirmed using XRD phase analysis.

Fig. 13 and 14 show the saturation magnetization and the coercivity plots of Pani- $\mathrm{BaFe}_{12} \mathrm{O}_{19}$ composites at different $\mathrm{BaFe}_{12} \mathrm{O}_{19}$ ratio according each synthesis. A linear increase of $\mathrm{Ms}$ is observed with increasing ferrite weight fraction, whereas, Hc values are independent of the mass ratio. However, there is a marked decrease of coercivity field compared to that of barium hexaferrite which is well observed for ABPNS composites (a decrease of 30\%). These changes of Ms and Hc values are mainly associated to uneven distribution, content of $\mathrm{BaFe}_{12} \mathrm{O}_{19}$ in the sample and the synthesis medium $[59,60]$.

According to the physical point of view, the magnetic properties of a material are related to the magnetic polarization $\mathrm{J}$ proportional to the magnetization. Generally, measuring methods to determinate the magnetic properties of the sample are in terms of moment per unit mass $(\mathbf{M})$. So, the magnetic polarization can be written following the relation 


$$
\mathbf{J}=\mu_{0} \rho \mathbf{M}
$$

with $\mu_{0}$ is the magnetic permeability of the vacuum with numerical value $4 \pi 10^{-7}$ henry/meter and $\rho$ is the volumic mass of the sample

In case of a composite formed by a mixture of two phases, $J$ depends on the volume fraction and the magnetic polarization of the phases. For Polyaniline- $\mathrm{BaFe}_{12} \mathrm{O}_{19}$, the magnetic polarization $\mathrm{J}_{\text {Composite }}$ may be expressed as

$$
\mathrm{J}_{\text {Composite }}=\varnothing_{\mathrm{HF}} \mathrm{J}_{\mathrm{HF}}+\left(1-\emptyset_{\mathrm{HF}}\right) \mathrm{J}_{\mathrm{P}}
$$

with $\emptyset_{\mathrm{HF}}$ and $\mathrm{J}_{\mathrm{HF}}$ are the volume fraction and the magnetic polarization of $\mathrm{BaFe}_{12} \mathrm{O}_{19}$, respectively. $\mathrm{J}_{\mathrm{P}}$ is the magnetic polarization of Pani.

The magnetic polarization of polyaniline is written as

$$
J_{P}=\mu_{0} \rho_{P} M_{P}
$$

where $\rho_{P}$ and $M_{P}$ are the volumic mass and the magnetization of Pani, respectively.

Indeed, $\mathrm{M}_{\mathrm{P}}$ of polyaniline is given by

$$
\mathrm{M}_{\mathrm{P}}=\chi_{\mathrm{P}} \mathrm{H}
$$

with $\chi_{\mathrm{P}}$ is the magnetic susceptibility of the Pani which is $<<10^{-3}$ and $\mathrm{H}$ is the magnetic field strength.

Knowing that $\mathrm{J}_{\mathrm{HF}}$ of barium hexaferrite

$$
\mathrm{J}_{\mathrm{HF}}=\mu_{0} \rho_{\mathrm{HF}} \mathrm{M}_{\mathrm{HF}}
$$

Where $\rho_{\mathrm{HF}}$ and $\mathrm{M}_{\mathrm{HF}}$ are the volumic mass and the magnetization of $\mathrm{BaFe}_{12} \mathrm{O}_{19}$, respectively.

By analogy with eq (4), $\mathrm{J}_{\mathrm{P}}<<\mathrm{J}_{\mathrm{HF}}$ and eq (2) becomes

$$
\begin{gathered}
\mathbf{J}_{\text {Composite }}=\emptyset_{\mathrm{HF}} \mathrm{J}_{\mathrm{HF}} \\
\mathrm{J}_{\text {Composite }}=\emptyset_{\mathrm{HF}} \mu_{0} \rho_{\mathrm{HF}} \mathrm{M}_{\mathrm{HF}}
\end{gathered}
$$

As reported in the literature, the magnetic polarization is strongly dependent to the real particle loading in the formed composite. Actually, the used initial loading to synthesize the samples can change after the polymerizations due to partial loss or dissolution during the fabrication [61-63]. Considering that, real weight fraction $\mathrm{w}_{\mathrm{rHF}}$ of the samples may be determined by using measured $\mathrm{M}_{\mathrm{s}}$ in Table 4 as

$$
\mathrm{w}_{\mathrm{rHF}}=\frac{\mathrm{M}_{\mathrm{sComposite}}}{\mathrm{M}_{\mathrm{sHF}}}
$$

And the magnetic polarization can be written as 


$$
\begin{aligned}
\mathrm{J}_{\text {Composite }} & =\mu_{0} \rho_{\text {Composite }} \mathrm{M}_{\text {Composite }} \\
& =\mu_{0} \rho_{\text {Composite }} \mathrm{W}_{\mathrm{rHF}} \mathrm{M}_{\mathrm{HF}}
\end{aligned}
$$

where $\rho_{\text {Composite }}$ is the volumic mass of the composite

The magnetic polarization of the composite is seen to be

$$
\begin{gathered}
\mathrm{J}_{\text {Composite }}=\emptyset_{\mathrm{HF}} \mu_{0} \rho_{\mathrm{HF}} \mathrm{M}_{\mathrm{HF}}=\mu_{0} \rho_{\text {Composite }} \mathrm{W}_{\mathrm{rHF}} \mathrm{M}_{\mathrm{HF}} \\
\emptyset_{\mathrm{HF}} \rho_{\mathrm{HF}}=\rho_{\text {Composite }} \mathrm{W}_{\mathrm{rHF}}
\end{gathered}
$$

The volume fraction can be deduced as follows

$$
\emptyset_{\mathrm{HF}}=\frac{\rho_{\text {Composite }}}{\rho_{\mathrm{HF}}} \mathrm{w}_{\mathrm{rHF}}
$$

To find the volume fractions $\emptyset_{\mathrm{HF}}$, real weight fraction $\mathrm{w}_{\mathrm{rHF}}$ of $\mathrm{BaFe}_{12} \mathrm{O}_{19}$ in the composites is calculated by using volumic mass densities of barium hexaferrite $\rho_{\mathrm{HF}}=5.32 \pm 0.02 \mathrm{~g} . \mathrm{cm}^{-3}$ [63], and polyaniline $\rho_{\mathrm{P}}$ $=1.5 \pm 0.1 \mathrm{~g} . \mathrm{cm}^{-3}[64]$. As known, the volumic mass densities of barium hexaferrite and Pani are as follows

$$
\begin{gathered}
\rho_{\mathrm{HF}}=\frac{m_{\mathrm{HF}}}{v_{\mathrm{HF}}} \\
\rho_{\mathrm{P}}=\frac{m_{\mathrm{P}}}{v_{\mathrm{P}}}
\end{gathered}
$$

where $\mathrm{m}_{\mathrm{HF}}$ and $\mathrm{v}_{\mathrm{HF}}$ are the weight and the volume of barium hexaferrite, respectively. $\mathrm{m}_{\mathrm{P}}$ and $\mathrm{v}_{\mathrm{P}}$ are the weight and volume of polyaniline, respectively.

To determine the volumic mass density of the composite $\rho_{\text {Composite, eq. (13) and (14) are used }}$

$$
\rho_{\text {Composite }}=\frac{m_{H F}+m_{P}}{\frac{m_{H F}}{\rho_{H F}}+\frac{m_{P}}{\rho_{P}}}
$$

The theoretical weight fraction of hexaferrite $\mathrm{w}_{\mathrm{tHF}}$ is given by

$$
\mathrm{w}_{\mathrm{tHF}}=\frac{\mathrm{m}_{\mathrm{HF}}}{\mathrm{m}_{\mathrm{HF}}+\mathrm{m}_{\mathrm{P}}}
$$

Introducing Eq. (16) into Eq. (15) leads to

The volumic mass density of the composites can be expressed as

$$
\rho_{\text {Composite }}=\frac{\rho_{\mathrm{HF}} \rho_{\mathrm{P}}}{\rho_{\mathrm{P}} \mathrm{W}_{\mathrm{tHF}}+\rho_{\mathrm{HF}}\left(1-\mathrm{w}_{\mathrm{tHF}}\right)}
$$

The volume fraction of ferrite in the composites can be deduced as 


$$
\emptyset_{\mathrm{HF}}=\frac{\rho_{\mathrm{P}} \mathrm{w}_{\mathrm{tHF}}}{\rho_{\mathrm{P}} \mathrm{w}_{\mathrm{tHF}}+\rho_{\mathrm{HF}}\left(1-\mathrm{w}_{\mathrm{tHF}}\right)}
$$

To determine the loading hexaferrite in the composites theoretical and real weight fractions are used

$$
\text { Loading }=\frac{\mathrm{w}_{\mathrm{rHF}}}{\mathrm{w}_{\mathrm{tHF}}} \times 100
$$

Table 5 lists the calculated values of real weight fractions, volume fraction and the loading of ferrite in the composites according to the previous equations. Hence, the calculated real weight fraction of $\mathrm{BaFe}_{12} \mathrm{O}_{19}$ in the composites is much lower than the theoretical weight fraction. However, solid-based polymerization presents the highest real weight and volume fraction which can be explained by a lower loss of ferrite particles during formation of composites in a solventless medium compared to the other routes in an aqueous medium.

In addition, the loading is globally between 40 and 50\% independently of synthesis route and quantity of ferrite except for the composites obtained by aqueous-based polymerization without stirring where lower coercivity, volume fraction and loading are observed. This may be associated to the mechanical stirring during polymerization which is believed to have a significant effect on the formed composites [65]. In fact, the barium hexaferrite can be dissolved with acidic chloride media [66]. The dissolution of the barium hexaferrite by acid attack includes the following steps [67, 68]:

The proton adsorption and ionic exchange, is described by,

$$
\begin{aligned}
& \equiv \mathrm{Fe}-\mathrm{OH}+\mathrm{H}^{+} \rightarrow \equiv \mathrm{Fe}-\mathrm{OH}_{2}{ }^{+} \\
& \equiv \mathrm{Ba}^{2+}+2 \mathrm{H}^{+} \rightarrow 2 \equiv \mathrm{H}^{+}+\mathrm{Ba}^{2+}
\end{aligned}
$$

The dissolution of iron from the surface of the external layer, coupled with barium diffusion across this layer is presented as

$$
\begin{aligned}
& \equiv \mathrm{Fe}^{3+} \rightarrow \mathrm{Fe}^{3+} \\
& \equiv \mathrm{Ba}^{2+} \rightarrow \mathrm{Ba}^{2+}
\end{aligned}
$$

where the symbol $\equiv$ characterizes the bonds linking the surface species to the solid structure. S. Jacobo and al [66] reported the evolution of the acid attack on barium hexaferrite and found that the iron dissolution rate depends strongly on the $\mathrm{pH}$. As illustrated in Fig. 13, the coercivity of ABP and ABPNS composites is $0.108 \pm 0.001 \mathrm{~T}$ and $0.080 \pm 0.002 \mathrm{~T}$, respectively independent of ferrite fraction. However, the used $\mathrm{pH}$ was 1.6 for the two syntheses. It can be deduced that the mechanical stirring 
effect decreases the acid attack of the iron oxide layer and promotes the protection of the particles from dissolution. This fact is in agreement with XRD, which showed an increase of volume cell corresponding to an adsorption of protons and a decrease of ferrite size associated to the dissolution of iron.

\section{Conclusion}

Polyaniline-barium hexaferrite composites with different $\mathrm{BaFe}_{12} \mathrm{O}_{19}$ amount have been synthesised by different pathways, namely, aqueous-based polymerization, solid-based polymerization, aqueous-based polymerization without stirring and aqueous-based polymerization with a post-synthesis mechanical grinding. Structural and morphological studies show a stronger interaction between hexaferrite and Pani for samples obtained by solid-based method. These structures exhibit less degree of agglomerations and reveal a good thermal stability than the other pathways. This good stability increases with the increasing ferrite content. All Pani-BaFe ${ }_{12} \mathrm{O}_{19}$ composites show both electric and ferromagnetic properties. The electric conductivity of Pani- $\mathrm{BaFe}_{12} \mathrm{O}_{19}$ obtained by aqueous-based polymerization is greater than that by solid-based polymerization and decreases with the increase of barium hexaferrite content in composites. This great conductivity is related to a higher oxidation level and doping degree which are confirmed by FTIR analysis and thermal study. The magnetic properties of the samples are measured by vibrating sample magnetometer. A linear increase of Ms is observed with increasing ferrite weight fraction, whereas, Hc values are independent of the mass ratio. However, there is a marked decrease of coercivity field compared to that of barium hexaferrite which is well observed for samples prepared by aqueous-based polymerization without stirring. These measurements allow us to determine the volume fraction and the loading of barium ferrite in the composites. This loading is found to be depended of stirring effect and reaction medium. Solid-based polymerization presented the highest volume fraction and loading. In fact, for aqueous medium, ferrite particles are dissolved by acid attack during polymerization that can be reduced by a mechanical stirring. Thus, the solid-based polymerization is found to be easy, economical, environmentally friendly synthesis and suitable for mass production of Pani- $\mathrm{BaFe}_{12} \mathrm{O}_{19}$ composites with good structural, physical and magnetic properties in view of electromagnetic applications.

\section{Acknowledgments}

The authors are grateful for the funding obtained from Université de Tunis El Manar, Higher Education and scientific Research in Tunisia to achieve this work and acknowledges the financial support received within the framework of scholarship for international students at SATIE, ENS de Cachan for 12 months. The authors are highly thankful to Arnaud Brosseau, assistant engineer in instrumentation and 
instrumental techniques in ENS Cachan (France), for his technical assistance with the FTIR and TGA measurement.

\section{References}

[1] G.R. Pedro, Hybrid organic-inorganic materials-in search of synergic activity, Adv. Mater., 13 (2001) 163-174.

[2] P.T. Nguyen, U. Rammelt, W. Plieth, Electrochemical impedance spectroscopy for characterization of coatings with intrinsically conducting polymers, Macromol. Symp. 187 (2002) 929-938.

[3] B. Garcia, A. Lamzoudi, F. Pillier, H. Nguyen Thi Le, C. Deslouis,Oxide/Polypyrrole composite films for corrosion protection of iron, J. Electrochem. Soc. 149 (2002) 560-566.

[4] A. Bhattacharya, A. De, Conducting composites of polypyrrole and polyaniline a review, Prog. Solid State Ch. 24 (1996) 141-181.

[5] H. Ahmad, Magnetic polyaniline composites: recent developments in preparation, properties and applications, J. Colloid Sci. Biotechnol. 2 (2013) 155-170.

[6] Y. Wang, Microwave absorbing materials based on polyaniline composites: a review, Int. J. Mater. Res. 105 (2014) 3-12.

[7] M.X. Wan, J.H. Fan, Synthesis and ferromagnetic properties of composites of a water-soluble polyaniline copolymer containing iron oxide, J. Polym. Sci. Part A: Polym. Chem. 36 (1998) 27492755.

[8] J. Zhao, Y. Xie, C. Yu, Z. Le, R. Zhong, Y. Qin, J. Pan, F. Liu, Preparation and characterization of the graphene-carbon nanotube / $\mathrm{CoFe}_{2} \mathrm{O}_{4} /$ polyaniline composite with reticular branch structures, Mater. Chem. Phys. 123 (2013) 395-402.

[9] Y. Xie, X. Hong, C. Yu, M. Li, Y. Huang, Y. Gao, J. Zhao, S. Yan, K. Zhang, Q. Lai, Y. Ling, Preparation and magnetic properties of poly(3-octyl-thiophene) $/ \mathrm{BaFe}_{11.92}(\mathrm{LaNd})_{0.04} \mathrm{O}_{19^{-}}$ titanium dioxide/ multiwalled carbon nanotubes nanocomposites, Compos. Sci. Technol. 77 (2013) 813

[10] J. Zhao, Y. Xie, M. Li, F. Xu, Z. Le, Y. Qin, D. Zhou, Z. Wang, H. Xu, J. Pan, Y. Ling, Preparation of magnetic-conductive $\mathrm{Mn}_{0.6} \mathrm{Zn}_{0.4} \mathrm{Fe}_{2} \mathrm{O}_{4}$-CNTs /PANI nanocomposites through hydrothermal synthesis coupled with in situ polymerization, Compos. Sci. Technol. 99 (2014) 147-153 [11] Y. Xie, J. Zhao, Z. Le, M. Li, J. Chen, Y. Gao, Y. Huang, Y. Qin, R. Zhong, D. Zhou, Y. Ling, Preparation and electromagnetic properties of chitosan-decorated ferrite-filled multi-walled carbon nanotubes/polythiophene composites, Compos. Sci. Technol. 99 (2014) 141-146 
[12] X. Hong, Y. Xie, X. Wang, M. Li, Z. Le, Y. Gao, Y. Huang, Y. Qin, Y. Ling, A novel ternary hybrid electromagnetic wave-absorbing composite based on $\mathrm{BaFe}_{11.92}(\mathrm{LaNd})_{0.04} \mathrm{O}_{19}$-titanium dioxide/multiwalled carbon nanotubes/polythiophene, Compo. Sci. Technol. 117 (2015) 215-224.

[13] G. CiricMarjanovic, Recent advences in polyaniline research: Polymerization mechanisms, structurl aspects and applications, Synth. Met. 177 (2013) 1-47.

[14] A. De Souza Gomes, New polymers for special applications, InTech, (2012).

[15] A.G. MacDiarmid, Synthetic metals: A novel role for organic polymers (Nobel Lecture), Angew. Chem. Int. Ed. 40 (2001) 2581-2590.

[16] H. Nguyen Cong, V. De laGarzaGuadarrama, J.L. Gautier, P. Chartier, Oxygen reduction on $\mathrm{Ni}_{\mathrm{x}} \mathrm{Co}_{3-\mathrm{x}} \mathrm{O}_{4}$ spinel particles/polypyrrole composite electrodes: hydrogenperoxide formation, Electrochim. Acta. 48 (2003) 2389-2395.

[17] H. Nguyen Cong, V. de la Garza Guadarrama, J.L. Gautier, P. Chartier, $\mathrm{Ni}_{\mathrm{x}} \mathrm{Co}_{3-\mathrm{x}} \mathrm{O}_{4}$ mixed valence oxide nanoparticles/polypyrrole composite electrodes for oxygen reduction, J. New Mater. Electrochem. Syst. 5 (2002) 35-40.

[18] Y. Liua, M.G.B. Drewb, Y. Liua, Optimizing the methods of synthesis for barium hexagonal ferrite-An experimental and theoretical study, Mater. Chem. Phys. 134 (2012) 266-272.

[19] M.K. Song, Y.T. Kim, B.S. Kim, J. Kim, K. Char, H.W. Rhee, Synthesis and characterization of soluble polypyrrole doped with alkylbenzenesulfonic acids, Synth. Met. 141 (2004) 315-319.

[20] D.A. Makeiff, T. Huber, Microwave absorption by polyaniline-carbon nanotube composites, Synth. Met. 156 (2006) 497-505.

[21] P. Xu, X. Han, J. Jiang, X. Wang, X. Li, A. Wen, Synthesis and characterization of novel coralloid polyaniline/BaFe ${ }_{12} \mathrm{O}_{19}$ nanocomposites, J. Phys. Chem. C111 34 (2007) 12603-12608.

[22] C.C. Yang, Y.J. Gung, W.C. Hung, T.H. Ting, K.H. Wub, Infrared and microwave absorbing properties of $\mathrm{BaTiO}_{3} /$ polyaniline and $\mathrm{BaFe}_{12} \mathrm{O}_{19}$ / polyaniline composites, Compos. Sci. and Technpl. 70 (2010) 466-471.

[23] T. Ting, K. Wu, Synthesis, characterization of polyaniline/ $\mathrm{BaFe}_{12} \mathrm{O}_{19}$ composites with microwave-absorbing properties, J. Magn. Magn Mater. 322 (2010) 2160-2166.

[24] M. Ferrari, L. Lutterotti, Method for the simultaneous determination of anisotropic residual stresses and texture by X-ray diffraction, J. Appl. Phys. 76 ( 1994) 7246-7255.

[25] M. Drofenika, I. Bana, D. Makovec, A. Znidarsicc, Z. Jaglicic, D. Hanzel, D. Lisjak, The hydrothermal synthesis of super-paramagnetic barium hexaferrite particles, Mater. Chem. Phys. 127, (2011) 415-419. 
[26] X.S. Du, C.F. Zjou, Y.W. Mai, Facile synthesis of hierarchical polyaniline nanostructures with dendritic nanofibers as scaffolds, J. Phys. Chem. C 112 (2008) 19836-19840.

[27] X. Obradors, A. Collomb, M. Pernet, D. Samaras, J.C. Joubert, X-ray analysis of the structural and dynamic properties of $\mathrm{BaFe}_{12} \mathrm{O}_{19}$ hexagonal ferrite at room temperature, J. Solid. State Chem. 56 (1985) 171-181.

[28] H.F. Yu, H.Y. Lin, Preparation and thermal behavior of aerosol-derived $\mathrm{BaFe}_{12} \mathrm{O}_{19}$ nanoparticles, J. Magn. Magn. Mater. 283 (2004) 190-198.

[29] D. Mishraa, S. Ananda, R.K. Pandab, R.P. Dasa, Studies on characterization, microstructures and magnetic properties of nano-size barium hexa-ferrite prepared through a hydrothermal precipitationcalcination route, Mater. Chem. Phys. 86 (2004) 132-136.

[30] A. Wolter, P. Rannou, J.P. Travers, Model for aging in HCl-protonated polyaniline: structure, conductivity, and composition studies, Phys. Rev. B 58 (1998) 7637-7647.

[31] K. Singha, A. Ohlana, R.K. Kotnala, A.K. Bakhshi, S.K. Dhawana, Dielectric and magnetic properties of conducting ferromagnetic composite of polyaniline with $\mathrm{Fe}_{2} \mathrm{O}_{3}$ nanoparticles, Mater. Chem. Phy. 112 (2008) 651-658.

[32] J. Stejskal, I. Sapurima, J. Prokes, J. Zemek, In-situ polymerized polyaniline films, Synth. Met. 105 (1999) 195-202.

[33] E.N. Konyushenko, J. Stejskal, I. Sedenkova, I. Sapurina, M. Cieslar, J. Prokes, Polyaniline nanotubes: conditions of formation, Polym. Int. 55 (2006) 31-39.

[34] U.S. Sajeev, C.J. Mathai, S. Saravanan, R.R. Ashokan, S. Venkatachalam, M.R. Anantharaman, On the optical and electrical properties of rf and ac. plasma polymerized aniline thin films, Bull. Mater. Sci. 29 (2006) 159-163.

[35] V.M. Mzenda, S.A. Goodman, F.D. Auret, L.C. Prinsloo, Characterization of electrical charge transfer in conducting polyaniline over the temperature range $300<\mathrm{T}(\mathrm{K})<450$, Synth. Met. 127 (2002) 279-283.

[36] N. Gospodinova, L. Trlemezyan, Conducting polymers prepared by oxidative polymerization: polyaniline, Prog. Polym. Sci. 23 (1998) 1443-1484.

[37] W. Shao, R. Jamal, F. Xu, A. Ubul, T. Abdiryim, The effect of a small smount of water on the structure and electrochemical properties of solid-State synthesized polyaniline, Materials 5 (2012) 1811-1825.

[38] J. Huang, J.A. Moore, J.H. Acquaye, R.B. Kaner, Mechanochemical route to the conducting polymer polyaniline, Macromolecules 38 (2005) 317-321. 
[39] M. Angelopoulosa, G.E. Asturias, S.P. Ermer, A. Ray, E.M. Scherr, A. G. Macdiarmid, M. Akhtar, Z. Kiss, A. J. Epstein, Polyaniline: Solutions, Films and Oxidation State, Mol. cryst. Liq. Cryst. Inc. nonlinear opt. 160 (1988) 151-163.

[40] L.A. Garcia-Cerda, S.M. Montemayor, Synthesis of $\mathrm{CoFe}_{2} \mathrm{O}_{4}$ nanoparticles embedded in a silica matrix by the citrate precursor technique, J. Magn. Magn. Mater. 294 (2005) 43-46.

[41] Y. Ahn, E.J. Choi, E.H. Kim, Superparamagnetic relaxation in cobalt ferrite nanoparticles synthesized from hydroxide carbonate precursors, Rev. Adv. Mater. Sci. 5 (2003) 477-480.

[42] I. Sapurina, A. Riede, J. Stejskal, In-situ polymerized polyaniline films: 3. Film formation, Synth. Met. 123 (2001) 503-507.

[43] W. Wang, S.P. Gumfekar, Q. Jiao, B. Zhao, Ferrite-grafted polyaniline nanofibers as electromagnetic shielding materials, J. Mater. Chem. C 1 (2013) 2851-2859.

[44] S. Bhadra, N. H. Kim, K.Y. Rhee, J. H. Lee, Preparation of nanosize polyaniline by solid-state polymerization and determination of crystal structure, Polym. Int. 58 (2009) 1173-1180.

[45] Y. Arai, Chemistry of Powder Production, first ed., Springer, Netherlands, 1996.

[46] E.N. Konyushenko, J. Stejskal, M. Trchova, J. Hradil, J. Kovarova, J. Prokes, M. Cieslar, J.Y. Hwang, K.H. Chen, I. Sapurina, Multi-wall carbon nanotubes coated with polyaniline, Polymer 47 (2006) 5715-5723.

[47] W. Dhaoui, S. Hbaieb, H. Zarrouk, A.B. Mohamed, Investigation of spectral properties, thermal stability, and morphology in polyaniline doped with Chlorocarboxylic Acids, Int. J. Polym. Anal. Charact. 11 (2006) 239-252.

[48] X. Li, W. Chen, C. Bain, J. He, N. Xu, G. Xue, Surface modification of $\mathrm{TiO}_{2}$ nanoparticles by polyaniline, Appl. Surf. Sci. 217 (2003), 16-22.

[49] S. Bhadra, D. Khastgir, Extrinsic and intrinsic structural change during heat treatment of polyaniline, Polym. Degrad. Stab. 93 (2008) 1094-1099.

[50] F.M. Smits, Measurement of sheet resistivities with the four-point probe, Bell Syst. Tech. J. 37 (1958) 711-718.

[51] A.J. Epstein, J.M. Ginder, F. Zuo, R.W. Bigelow, H.S. Woo, D.B. Tanner, A.F. Richter, W.S. Huang, A.G. Macdiarmid,Insulator-to-metal transition in polyaniline, Synth. Met. 18 (1987) 303-309.

[52] N, Munshi, T.K. De, A. Maitra, Size modulation of polymeric nanoparticles under controlled dynamics of microemulsion droplets, J. Colloid. Interface. Sci. 190 (1997) 387-391.

[53] V.N. Prigodin, A.J. Epstein, Quantum hopping in metallic polymers, Physica B 38 (2003) 310-317. 
[54] Y. M. Huang, F.F. Zhou, Z. She, C. Pan, Effect of mortar-pestle grinding on conductivity of ferric chloride doped polypyrrole, Key. Eng. Mater. 428 (2010) 497-500.

[55] P.S. Sidhu, R.J. Gilkes, R.M. Cornell, A.M. Posner, J.P. Quirk, Dissolution of iron oxides and oxyhydroxides in hydrochloric and perchloric acids, Clays Clay Miner. 29 (1981) 269-276.

[56] B. D. Cullity, C. D. Graham, Introduction to Magnetic Materials, second ed., Wiley-IEEE Press, (2008).

[57] B. Shirk, W. Buessem, Temperature dependence of Ms et $\mathrm{K} 1$ of $\mathrm{BaFe}_{12} \mathrm{O}_{19}$ and $\mathrm{SrFe}_{12} \mathrm{O}_{19}$ single cristals, J. Appl. Phys. 40 (1969) 1294-1296.

[58] X. Liu, J. Wang, L.M. Gan, S.C. Ng, Improving the magnetic properties of hydrothermally synthesized barium ferrite, J. Magn. Magn. Mater. 195 (1999) 452-459.

[59] P. Chitra, A. Muthusamy, R. Jayaprakash, E. R. Kumar, Effect of ultrasonication on particle size and magnetic properties of polyaniline $\mathrm{NiCoFe}_{2} \mathrm{O}_{4}$ nanocomposites, J. Magn. Magn. Mater. 366 (2014) 55-63.

[60] V. Babayan, N.E. Kazantseva, I. Sapurina, R. Moucka, J. Vilcakova, J. Stejskal, Magnetoactive feature of in-situ polymerised polyaniline film developed on the surface of manganese-zinc ferrite, Appl Surf. Sci. 258 (2012) 7707- 7716.

[61] Z. Guo, K. Shin, A.B. Karki, D.P. Young, R.B. Kaner, H.T. Hahn, Fabrication and characterization of iron oxide nanoparticles filled polypyrrole nanocomposites, J. Nanopart. Res. 11 (2009) 1441-1452.

[62] A. Eftekhari, Nanostructured conductive polymers, first ed.,Wiley, (2010).

[63] F. Sauzedde, A. Elaïssari, C. Pichot, Hydrophilic magnetic polymer latexes. 1- Adsorption of magnetic iron oxide nanoparticles into various cationic latexes, Colloid Polym. Sci. 277 (1999) 846855.

[64] J. Smit, H. P.J. Wijn, Ferrites: physical properties of ferromagnetic oxides in relation to their technical applications, first ed., Philips Technical Library, the Netherlands (1959).

[65] J. De Silvestro, W. Scheifele, Morphology of electrochemically prepared polyaniline, influence of polymerization parameters, J. Mater. Chem. 3 (1993) 263-272.

[66] S. Jacoboa, E. Regazzoni, M. A. Blesa, Interfacial chemistry of powdered barium ferrites immersed in aqueous solutions: leaching in acidic chloride media, J. Master Sci. 37 (2002) 3053-3057.

[67] M. Rosler, P. Girmert, E. Sinn, Structural and magnetic of Ba-ferrite fine particles grown by glass crystallization, Z. Phys. D Atom. Mol. CL 19 (1991) 279-281. 
[68] M.A. Blesa, P.J. Morando, A.E. Regazzoni, Chemical Dissolution of Metal Oxides, CRC Press, Boca Raton, (1994). 


\section{Tables Captions}

Table 1 Abbreviations of different syntheses pathways

Table 2 Lattice costants, unit cell volume and crystallite size of $\mathrm{BaFe}_{12} \mathrm{O}_{19}, 50 \mathrm{ABPN}, 50 \mathrm{SBP}$, 50ABPMG and50 ABPNS samples deermined using rietveld method

Table 3 Details of $\%$ weight loss at different temperature of prepard Pani- $\mathrm{BaFe}_{12} \mathrm{O}_{19}$ composites Table 4 Magnetic properties of $\mathrm{BaFe}_{12} \mathrm{O}_{19}$ and Polyaniline- $\mathrm{BaFe}_{12} \mathrm{O}_{19}$ composites prepared using differentes methods

Table 5 Theoritcal weight fraction $\mathrm{w}_{\mathrm{tHF}}$, real weight fraction $\mathrm{w}_{\mathrm{rHF}}$ and volume fraction $\varnothing_{\mathrm{HF}}$ of barium hexaferrite in Polyaniline- $\mathrm{BaFe}_{12} \mathrm{O}_{19}$ composites prepared by different syntheses 
Table 1

\begin{tabular}{|l|c|}
\hline Synthesis pathway & Abbreviation \\
\hline Aqueous-Based Polymerization & ABP \\
\hline Solid-Based Polymerization & SBP \\
\hline Aqueous-Based Polymerization Non Stirred & ABPNS \\
\hline Aqueous-Based Polymerization with Mechanical Grinding & ABMG \\
\hline
\end{tabular}


Table 2

\begin{tabular}{|c|c|c|c|c|}
\hline Sample & $\mathrm{a}(\mathrm{nm})$ & $\mathrm{c}(\mathrm{nm})$ & $\begin{array}{c}\text { Unit cell volume } \\
\left(\mathrm{nm}^{3}\right)\end{array}$ & $\begin{array}{c}\text { Crystallite size } \\
(\mathrm{nm})\end{array}$ \\
\hline $\mathrm{BaFe}_{12} \mathrm{O}_{19}$ & 0.589 & 2.323 & 0.697 & $134( \pm 2)$ \\
\hline $50 \mathrm{ABP}$ & 0.589 & 2.323 & 0.697 & $120( \pm 2)$ \\
\hline $50 \mathrm{SBP}$ & 0.589 & 2.323 & 0.697 & $120( \pm 2)$ \\
\hline $50 \mathrm{ABPMG}$ & 0.589 & 2.323 & 0.697 & $103( \pm 2)$ \\
\hline $50 \mathrm{ABPNS}$ & 0.589 & 2.333 & 0.700 & \\
\hline
\end{tabular}


Table 3

\begin{tabular}{|c|c|c|c|c|c|c|c|}
\hline \multicolumn{2}{|c|}{ Sample } & \multicolumn{2}{|c|}{ First Step } & \multicolumn{2}{|c|}{ Second step } & \multicolumn{2}{|c|}{ Third step } \\
\hline & & $\begin{array}{l}\text { Temperat } \\
\text { ure }\left({ }^{\circ} \mathrm{C}\right)\end{array}$ & $\begin{array}{c}\% \\
\text { weight } \\
\text { loss }\end{array}$ & $\begin{array}{l}\text { Temperat } \\
\text { ure }\left({ }^{\circ} \mathrm{C}\right)\end{array}$ & $\begin{array}{c}\% \\
\text { weight } \\
\text { loss }\end{array}$ & $\begin{array}{l}\text { Temperat } \\
\text { ure }\left({ }^{\circ} \mathrm{C}\right)\end{array}$ & $\begin{array}{c}\% \\
\text { weight } \\
\text { loss }\end{array}$ \\
\hline \multirow[t]{4}{*}{10} & $\mathrm{ABP}$ & 62.7 & 8.13 & 241 & 15.58 & 489 & 27.8 \\
\hline & SBP & 65.8 & 5.61 & 257 & 11.83 & 517 & 25.3 \\
\hline & $\begin{array}{l}\text { ABP } \\
\text { NS }\end{array}$ & 62.7 & 11.16 & 250 & 14.82 & 504 & 23.8 \\
\hline & $\begin{array}{l}\text { ABP } \\
\mathrm{MG}\end{array}$ & 65.2 & 8.25 & 285 & 16.8 & 510 & 25.1 \\
\hline \multirow[t]{4}{*}{50} & $\mathrm{ABP}$ & 63.7 & 6.04 & 246 & 12.55 & 519 & 24.2 \\
\hline & SBP & 65.5 & 3.98 & 266 & 11.50 & 532 & 22.1 \\
\hline & $\begin{array}{l}\mathrm{ABP} \\
\mathrm{NS}\end{array}$ & 62.5 & 10.45 & 256 & 7.53 & 525 & 21.7 \\
\hline & $\begin{array}{l}\text { ABP } \\
\mathrm{MG}\end{array}$ & 64.5 & 5.50 & 288 & 13.24 & 522 & 22.3 \\
\hline
\end{tabular}


Table 4

\begin{tabular}{|c|c|c|c|c|}
\hline Sample & $\begin{array}{l}\text { Synthesis } \\
\text { pathway }\end{array}$ & $\begin{array}{c}\mathrm{M}_{\mathrm{s}} \\
\left(\mathrm{Am}^{2} / \mathrm{Kg}\right)\end{array}$ & $\begin{array}{c}\mathrm{M}_{\mathrm{r}} \\
\left(\mathrm{Am}^{2} / \mathrm{Kg}\right)\end{array}$ & $\mu_{0} \mathrm{H}_{\mathrm{c}}(\mathrm{T})$ \\
\hline $\mathrm{BaFe}_{12} \mathrm{O}_{19}$ & Hydrothermal & 66.65 & 29.91 & 0.1118 \\
\hline \multirow[t]{4}{*}{10} & $\mathrm{ABP}$ & 3.30 & 1.19 & 0.1099 \\
\hline & SBP & 5.77 & 2.19 & 0.1083 \\
\hline & ABPMG & 4.58 & 2.55 & 0.1080 \\
\hline & ABPNS & 1.37 & 0.44 & 0.0816 \\
\hline \multirow[t]{4}{*}{30} & $\mathrm{ABP}$ & 8.25 & 3.51 & 0.1114 \\
\hline & SBP & 13.18 & 5.57 & 0.1094 \\
\hline & ABPMG & 9.45 & 4.13 & 0.1058 \\
\hline & ABPNS & 2.92 & 1.10 & 0.0783 \\
\hline \multirow[t]{4}{*}{50} & $\mathrm{ABP}$ & 13.36 & 5.76 & 0.1026 \\
\hline & SBP & 18.52 & 7.64 & 0.1030 \\
\hline & ABPMG & 14.75 & 6.27 & 0.1034 \\
\hline & ABPNS & 4.50 & 1.53 & 0.0782 \\
\hline \multirow[t]{4}{*}{70} & $\mathrm{ABP}$ & 20.06 & 8.72 & 0.1070 \\
\hline & SBP & 25.36 & 11.12 & 0.1026 \\
\hline & ABPMG & 21.97 & 7.79 & 0.1050 \\
\hline & ABPNS & 6.32 & 2.44 & 0.0822 \\
\hline
\end{tabular}


Table 5

\begin{tabular}{|c|c|c|c|c|c|}
\hline Sample & $\begin{array}{l}\text { Synthes } \\
\text { is pathway }\end{array}$ & $\begin{array}{l}\text { Theoretic } \\
\text { al } \mathrm{w}_{\mathrm{tHF}}\end{array}$ & $\begin{array}{l}\text { Real } \\
\mathrm{w}_{\mathrm{tHF}}\end{array}$ & $\begin{array}{c}\emptyset_{\mathrm{HF}} \text { in } \\
\text { the sample }\end{array}$ & $\begin{array}{c}\text { Loading } \\
\%\end{array}$ \\
\hline \multirow[t]{4}{*}{10} & $\mathrm{ABP}$ & 0.10 & 0.05 & 0.014 & 50 \\
\hline & SBP & 0.10 & 0.08 & 0.026 & 80 \\
\hline & $\begin{array}{l}\text { ABPM } \\
\text { G }\end{array}$ & 0.10 & 0.06 & 0.02 & 69 \\
\hline & ABPNS & 0.10 & 0.02 & 0.005 & 21 \\
\hline \multirow[t]{4}{*}{30} & $\mathrm{ABP}$ & 0.30 & 0.12 & 0.038 & 41 \\
\hline & SBP & 0.30 & 0.19 & 0.06 & 66 \\
\hline & $\begin{array}{l}\text { ABPM } \\
G\end{array}$ & 0.30 & 0.14 & 0.04 & 47 \\
\hline & ABPNS & 0.30 & 0.02 & 0.01 & 15 \\
\hline \multirow[t]{4}{*}{50} & $\mathrm{ABP}$ & 0.50 & 0.20 & 0.06 & 40 \\
\hline & SBP & 0.50 & 0.23 & 0.07 & 46 \\
\hline & $\begin{array}{l}\text { ABPM } \\
G\end{array}$ & 0.50 & 0.22 & 0.07 & 44 \\
\hline & ABPNS & 0.50 & 0.06 & 0.02 & 14 \\
\hline \multirow[t]{4}{*}{70} & $\mathrm{ABP}$ & 0.70 & 0.30 & 0.10 & 43 \\
\hline & SBP & 0.70 & 0.38 & 0.14 & 54 \\
\hline & $\begin{array}{l}\text { ABPM } \\
G\end{array}$ & 0.70 & 0.26 & 0.09 & 38 \\
\hline & ABPNS & 0.70 & 0.09 & 0.02 & 14 \\
\hline
\end{tabular}




\section{Figures Captions}

Figure 1. Flow chart of (a) solid-based (b) aqueous-based polymerization

Figure 2. X-Ray diffraction patterns of calcined $\mathrm{BaFe}_{12} \mathrm{O}_{19}$

Figure 3. X-Ray diffraction patterns of Polyaniline- $\mathrm{BaFe}_{12} \mathrm{O}_{19}$ composites obtained by a) $\mathrm{ABP}$, b) SBP, c) ABPNS and d) ABPMG

Figure 4. FTIR Spectra of a) $\mathrm{BaFe}_{12} \mathrm{O}_{19}$ and b) Polyaniline obtained by different routes

Figure 5. FTIR Spectra of Polyaniline- $\mathrm{BaFe}_{12} \mathrm{O}_{19}$ composites obtained by a) ABP, b) SBP, c) ABPNS and d) ABPMG routes

Figure 6. SEM microphotographs of calcined $\mathrm{BaFe}_{12} \mathrm{O}_{19}$

Figure 7. SEM microphotographs of Pani- $\mathrm{BaFe}_{12} \mathrm{O}_{19}$ nanocomposites obtained with ABP for 10 wt. $\%$ and 50 wt. \% and with SBP for 10 wt. \% and 50 wt. \%

Figure 8. SEM microphotographs of a) 10ABPNS, b) 50ABPNS, c) 10ABPMG and d) 50ABPMG samples

Figure 9. Thermogravimetric curves of Polyaniline- $\mathrm{BaFe}_{12} \mathrm{O}_{19}$ compositesof 10 and 50 ratio of hexaferrite obtained by different syntheses

Figure 10. Dc conductivity of Polyaniline- $\mathrm{BaFe}_{12} \mathrm{O}_{19}$ composites obtained by different pathways

Figure 11. Hysteresis loop of $\mathrm{BaFe}_{12} \mathrm{O}_{19}$

Figure 12. Hysteresis loops of Polyaniline- $\mathrm{BaFe}_{12} \mathrm{O}_{19}$ composites obtained by a)ABP, b) SBP, c) ASPNS and d) ASPMG routes

Figure 13. Variation of saturation magnetization of Polyaniline- $\mathrm{BaFe}_{12} \mathrm{O}_{19}$ composites obtained by different syntheses

Figure 14. Variation of coercivity of Polyaniline- $\mathrm{BaFe}_{12} \mathrm{O}_{19}$ composites obtained by different synrheses 
Fig. 1.

(a)

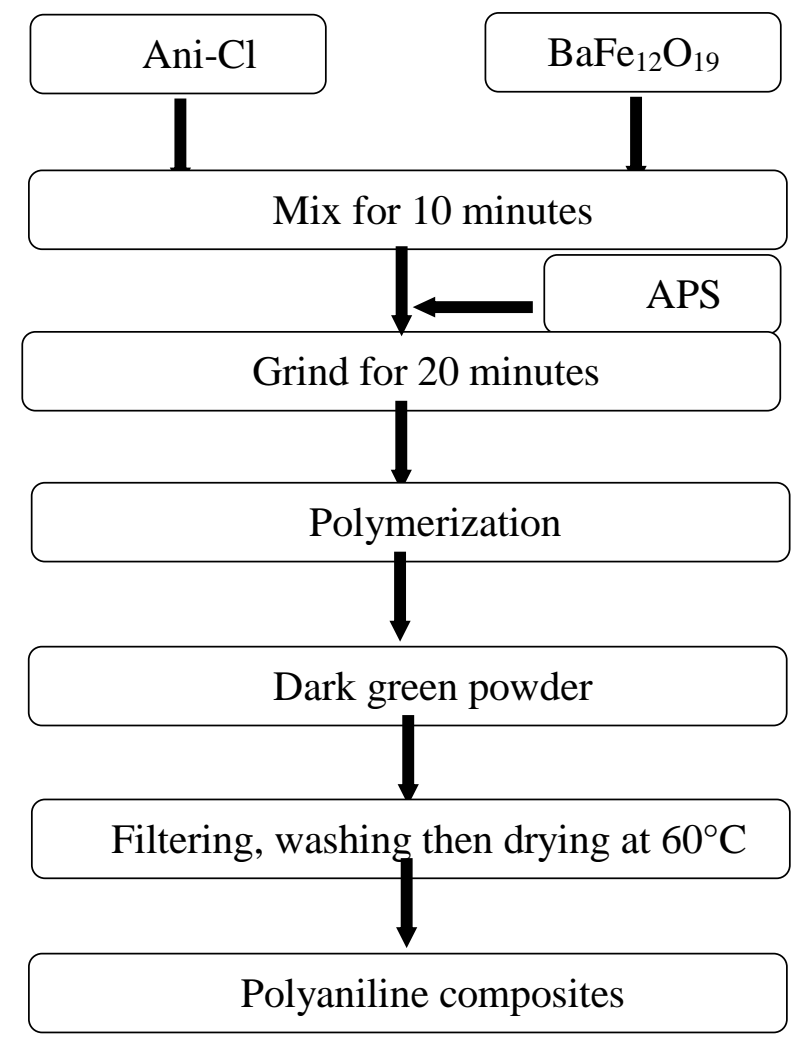

(b)

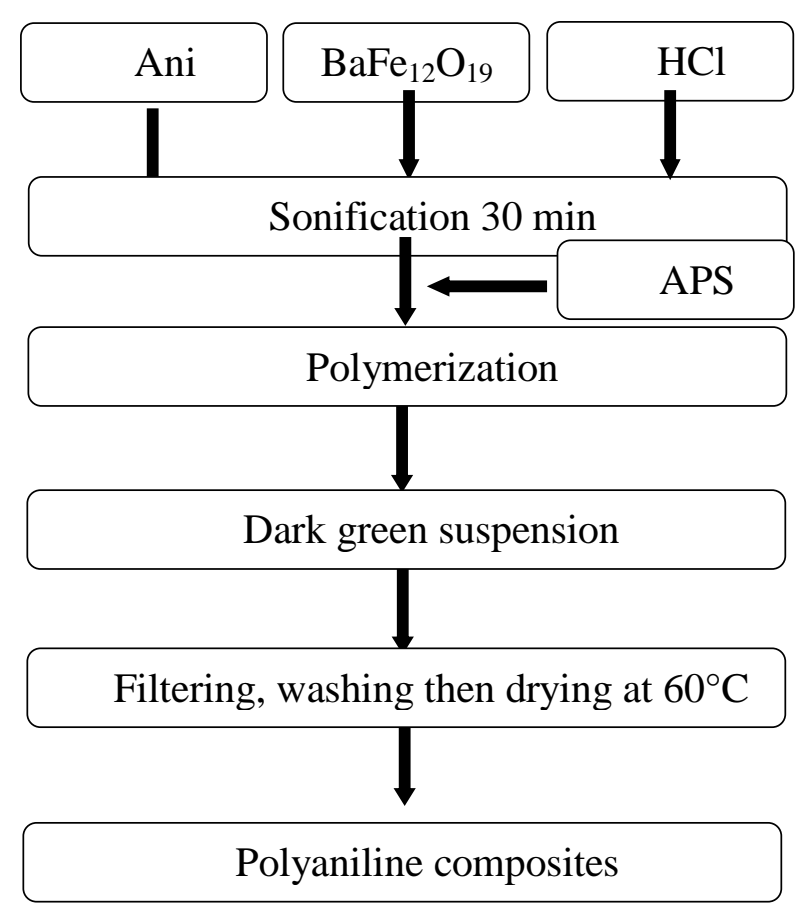


Fig. 2.

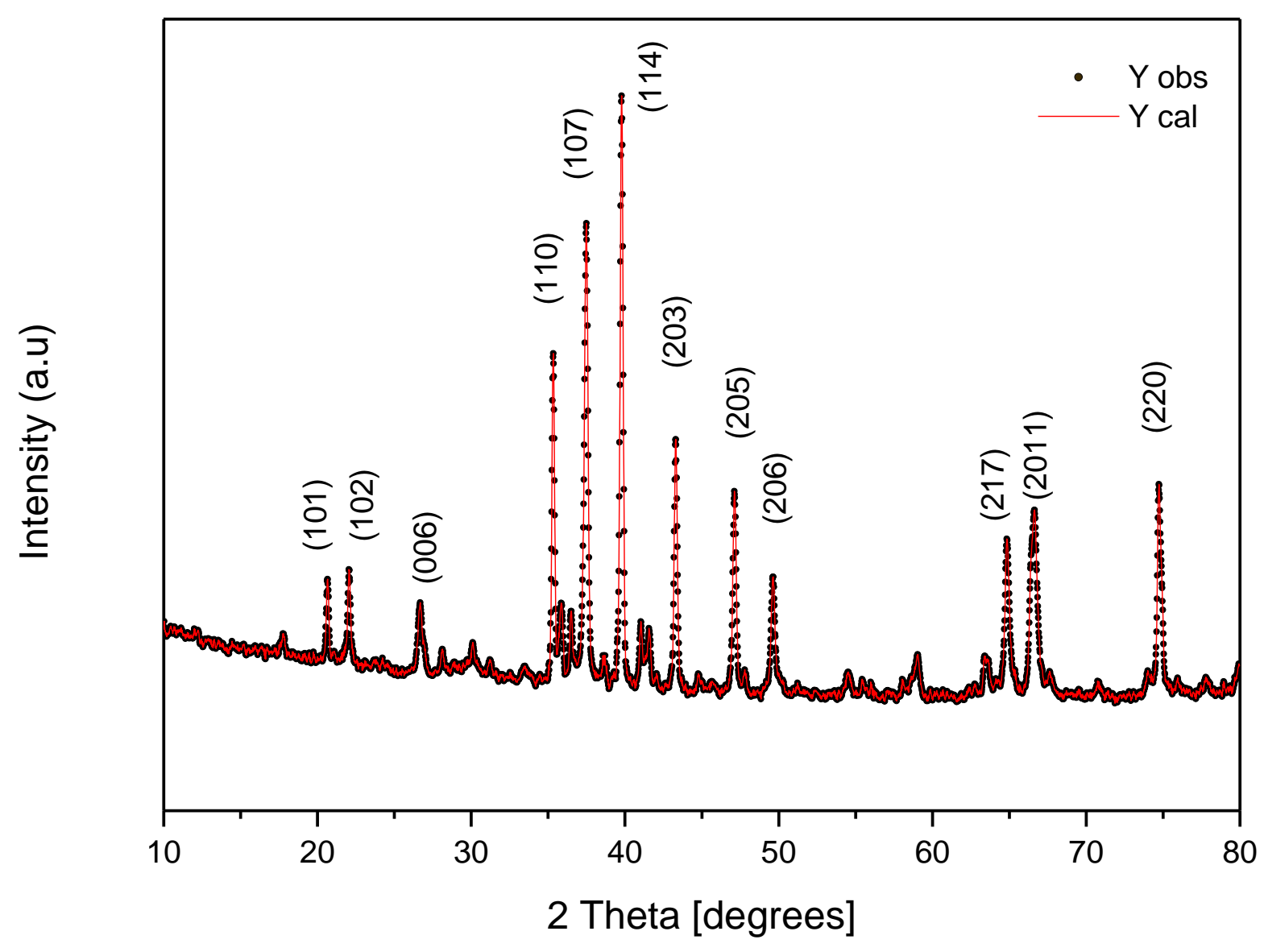


Fig. 3.
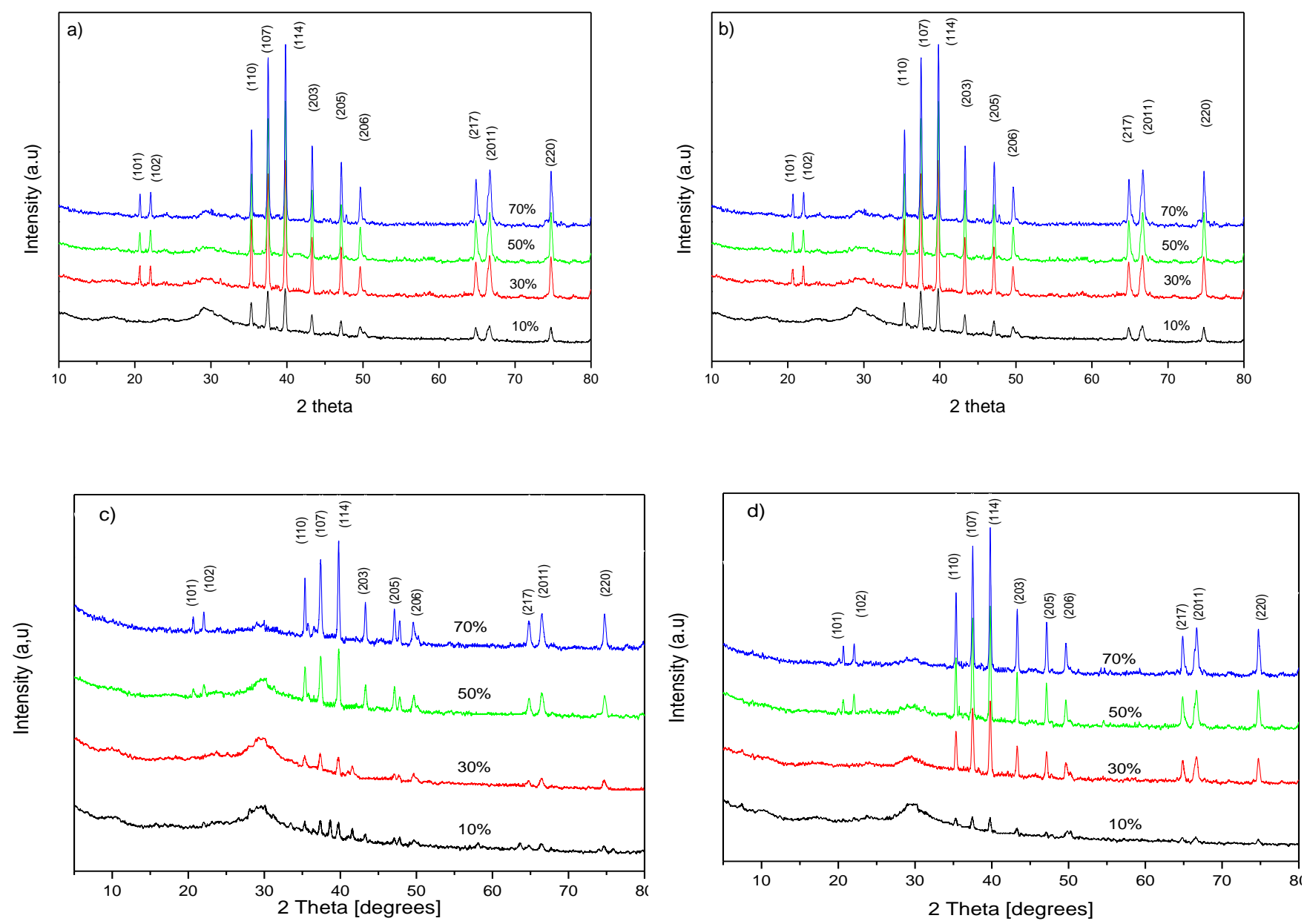
Fig. 4.
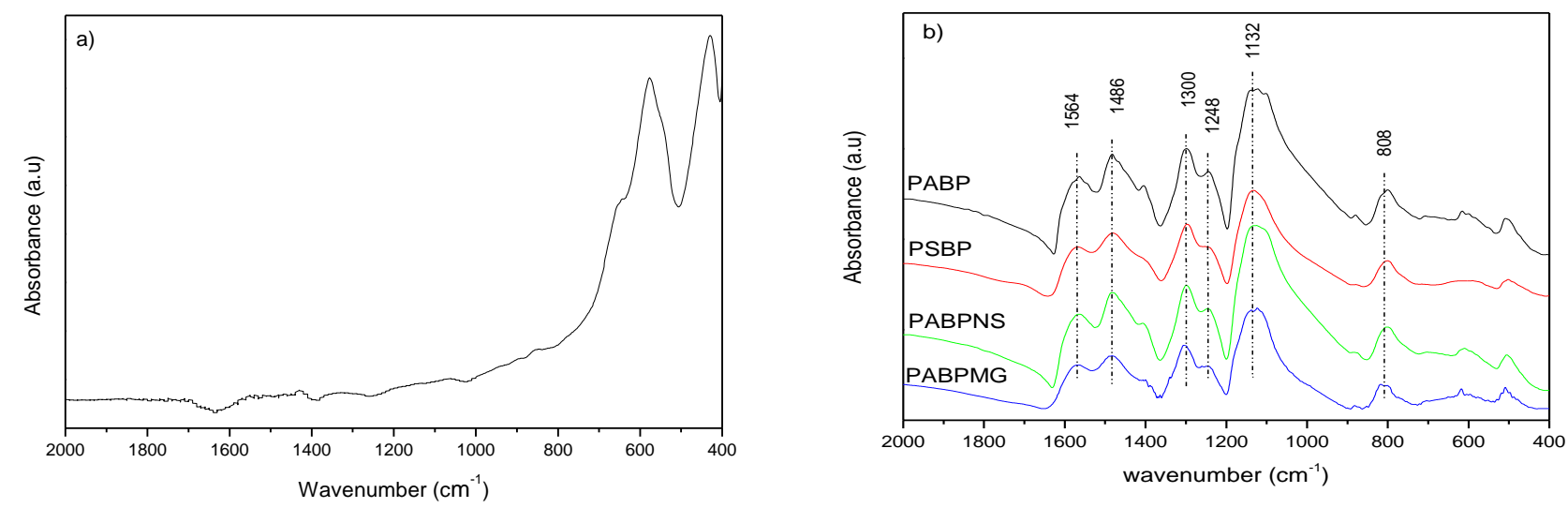
Fig. 5.
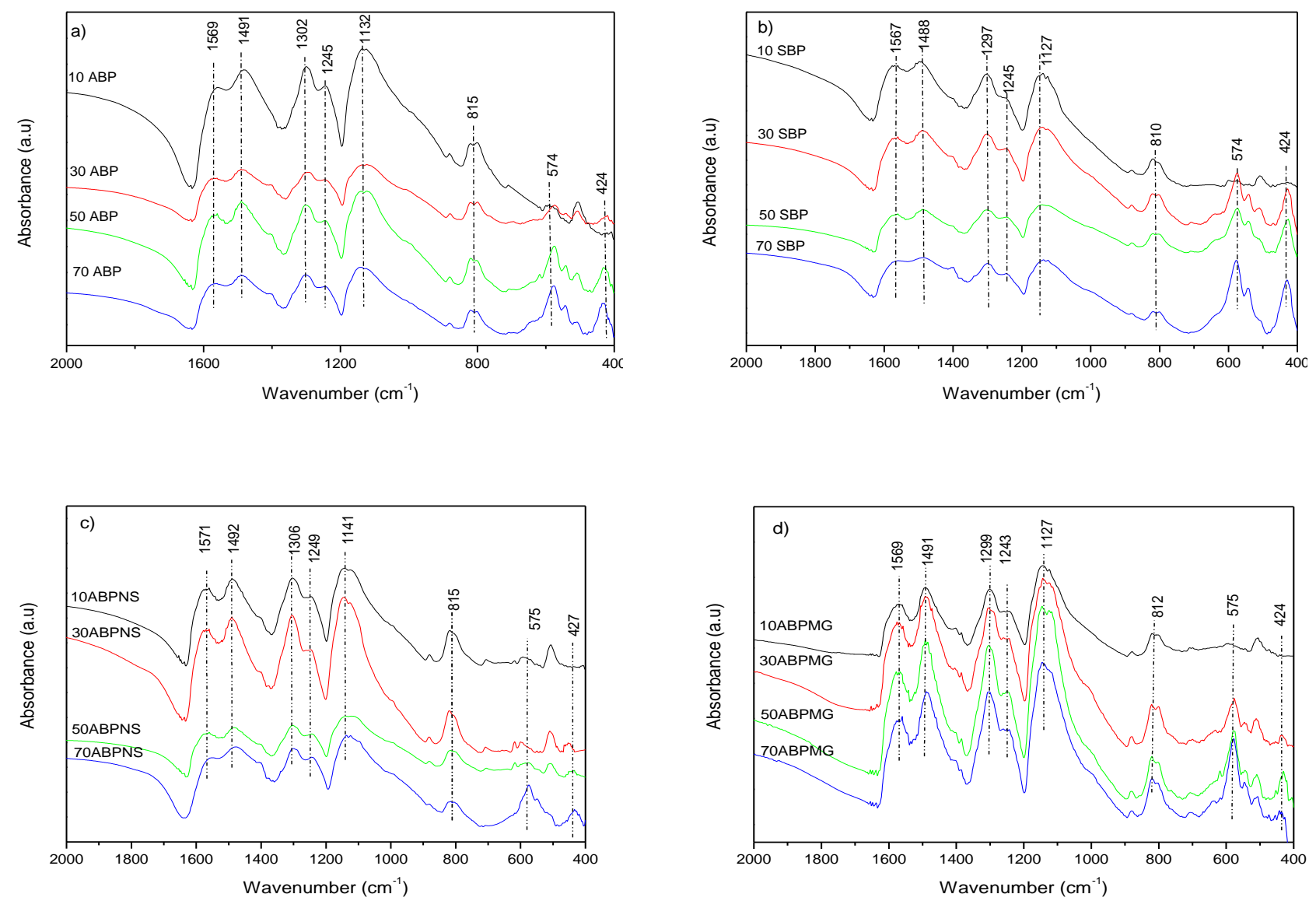
Fig. 6.

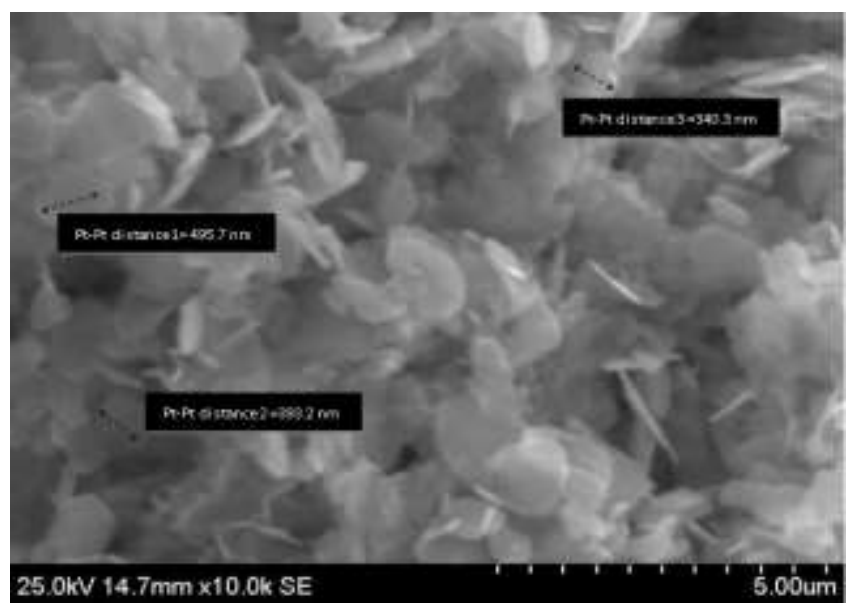


Fig. 7.
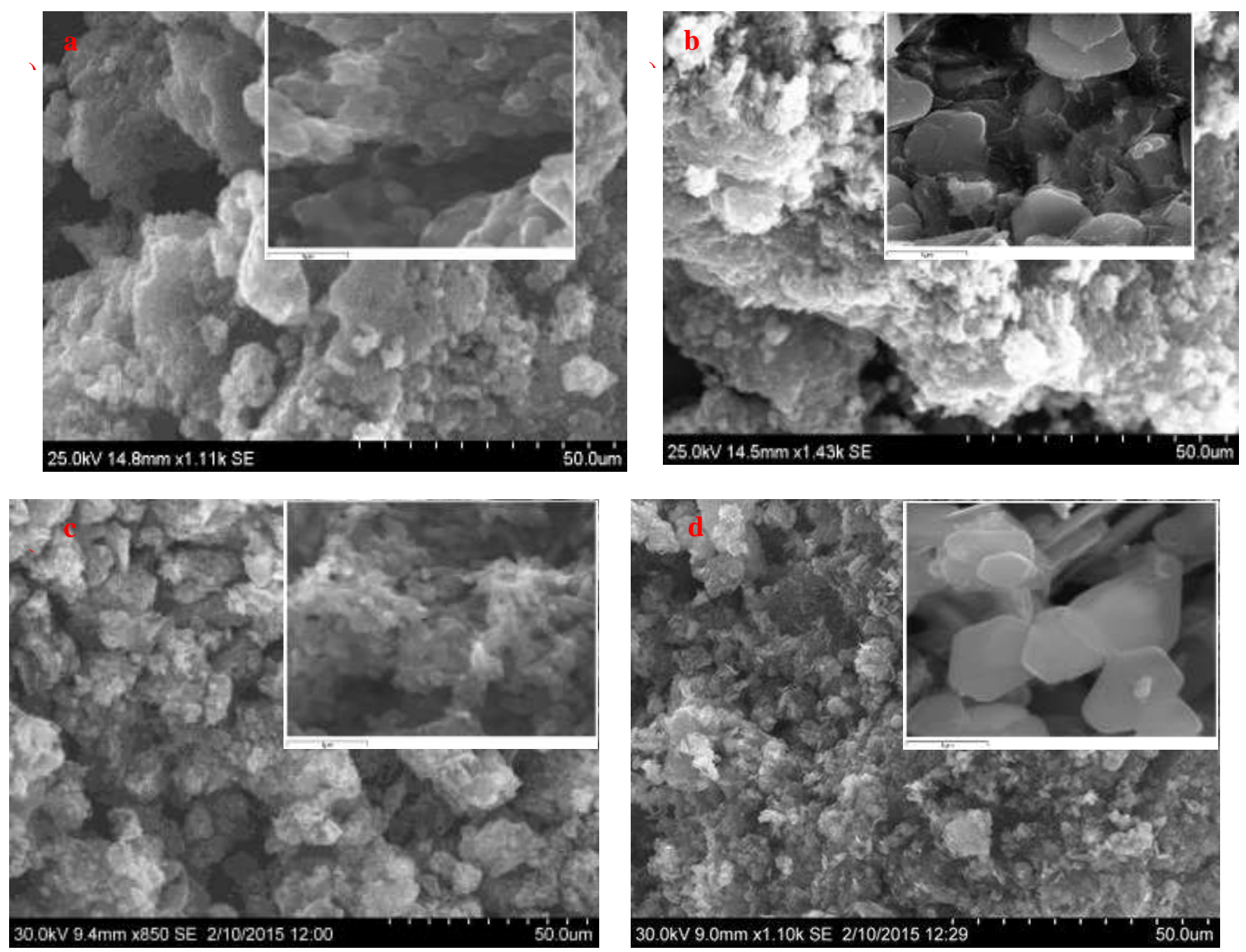
Fig. 8.
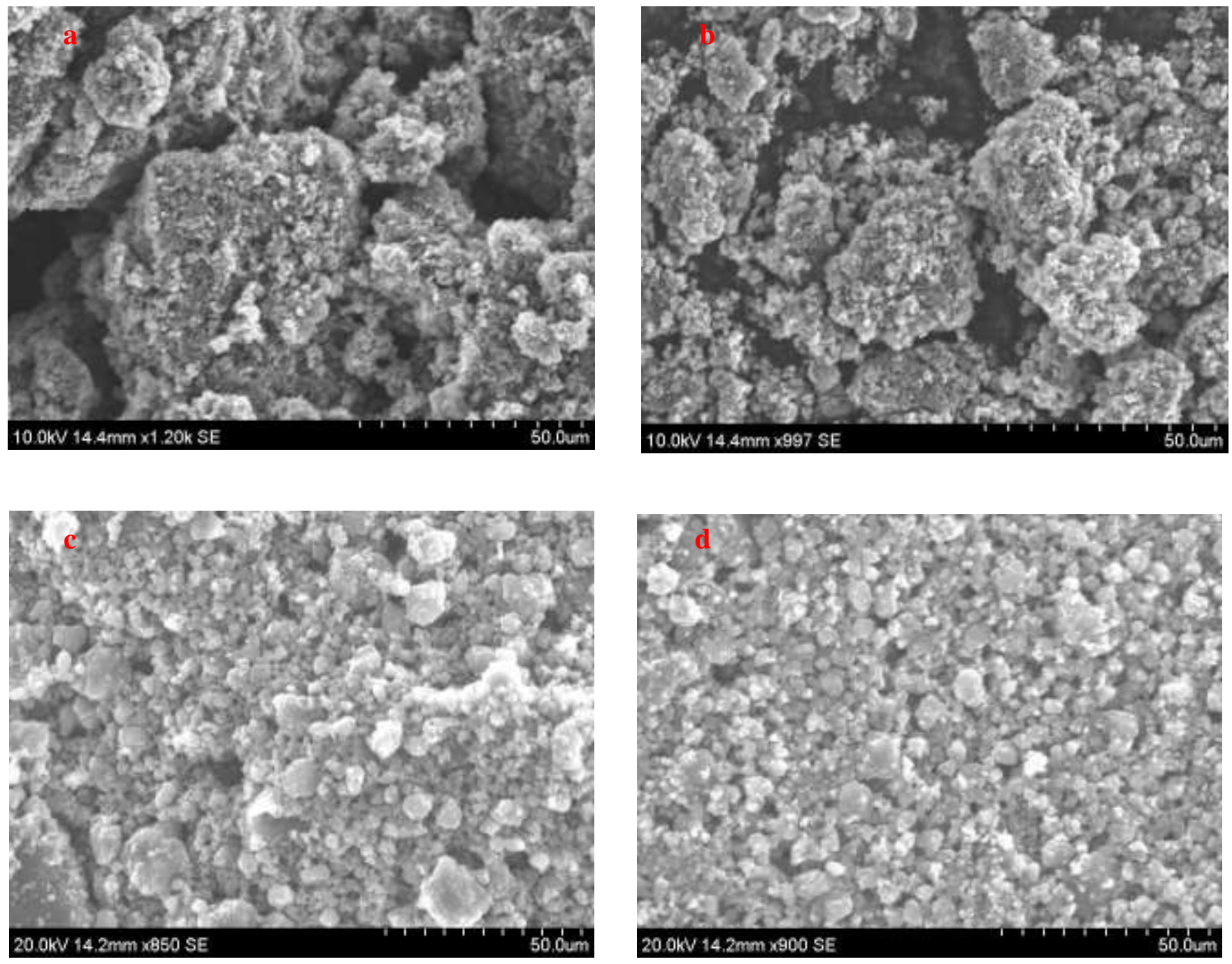
Fig. 9.
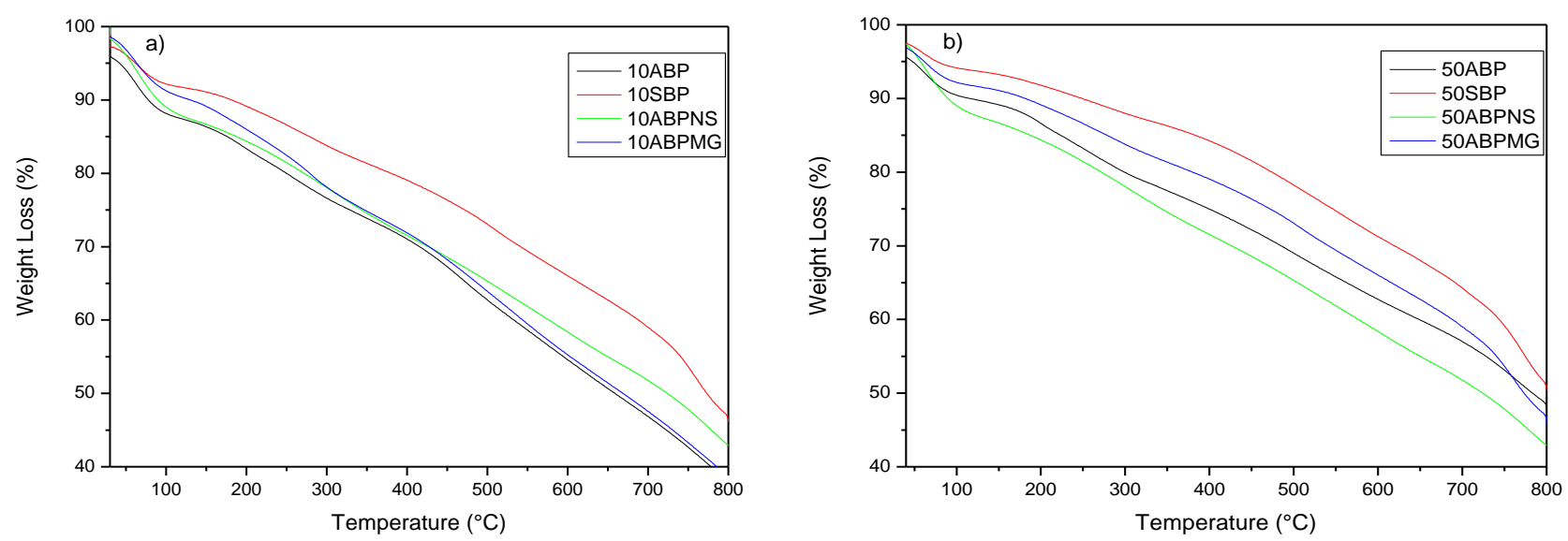
Fig. 10.

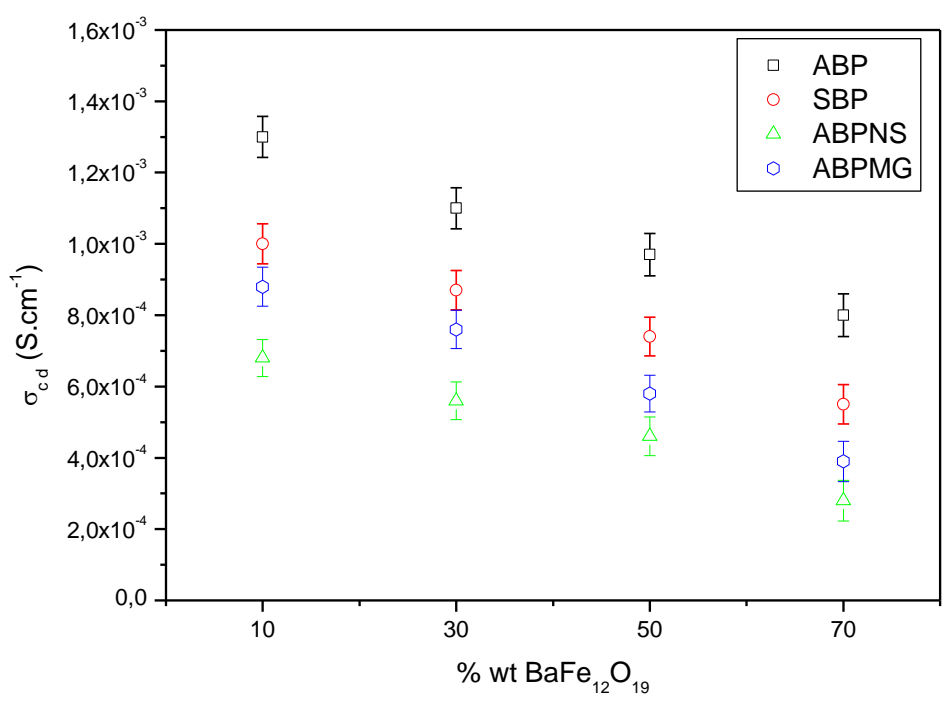


Fig. 11.

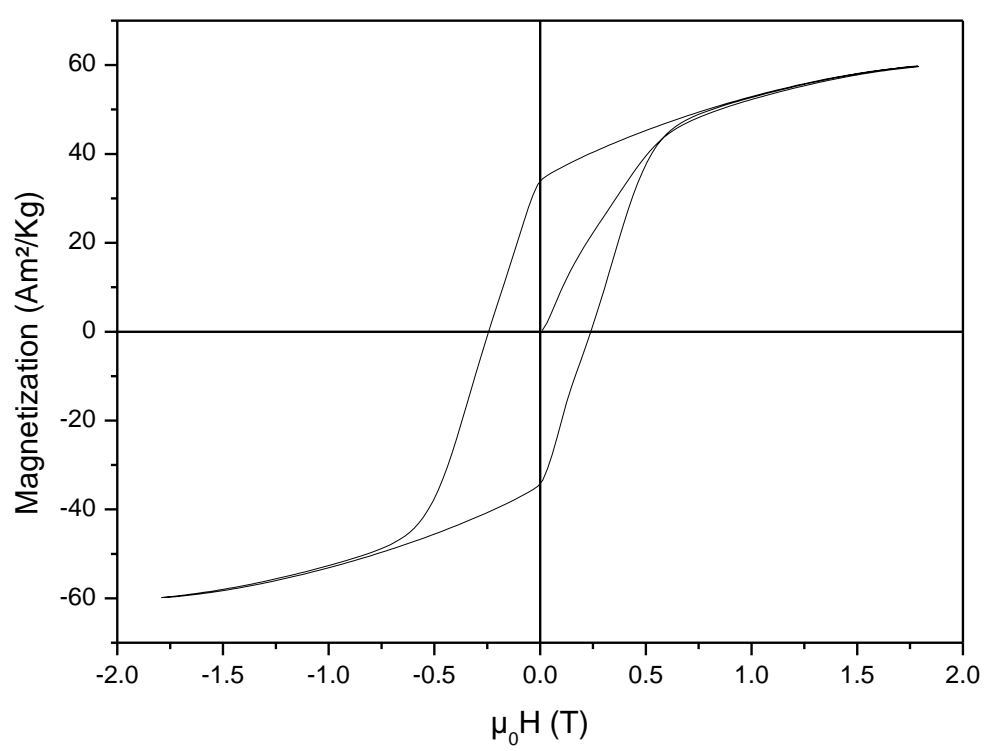


Fig. 12.
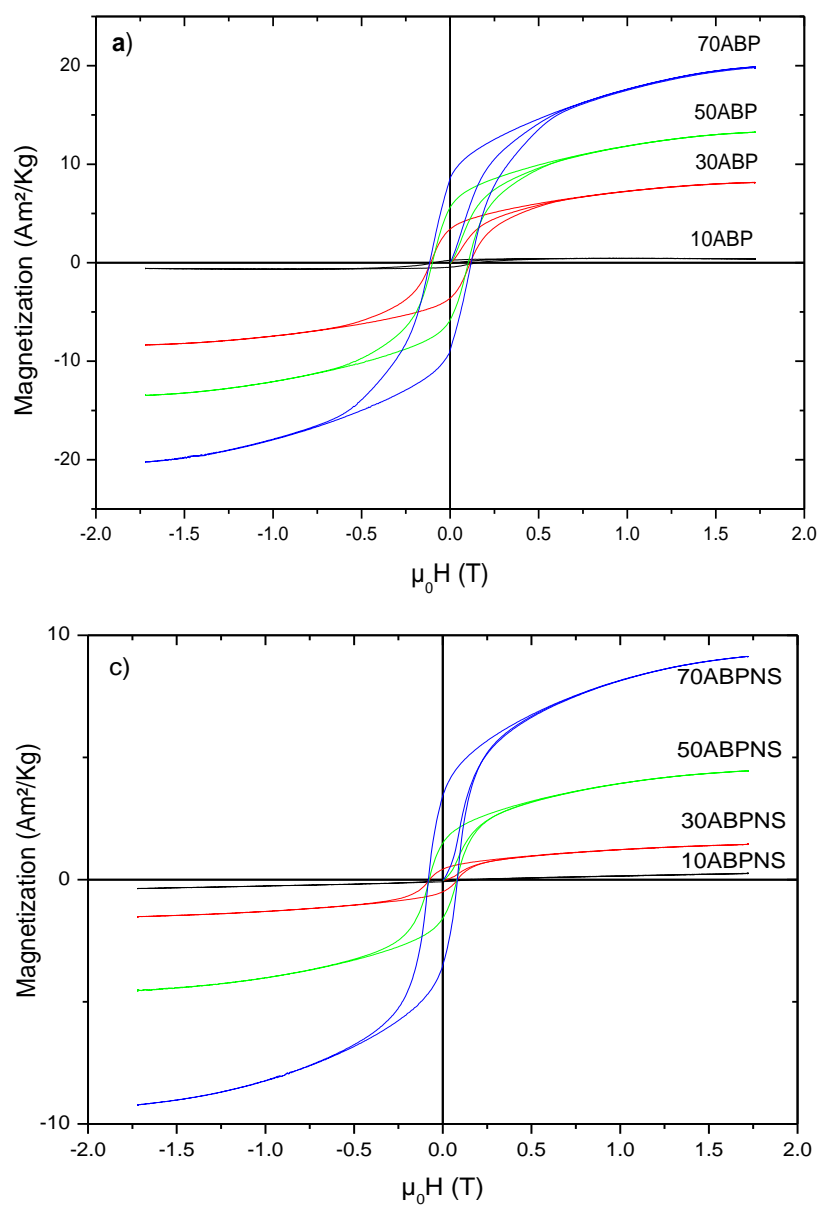
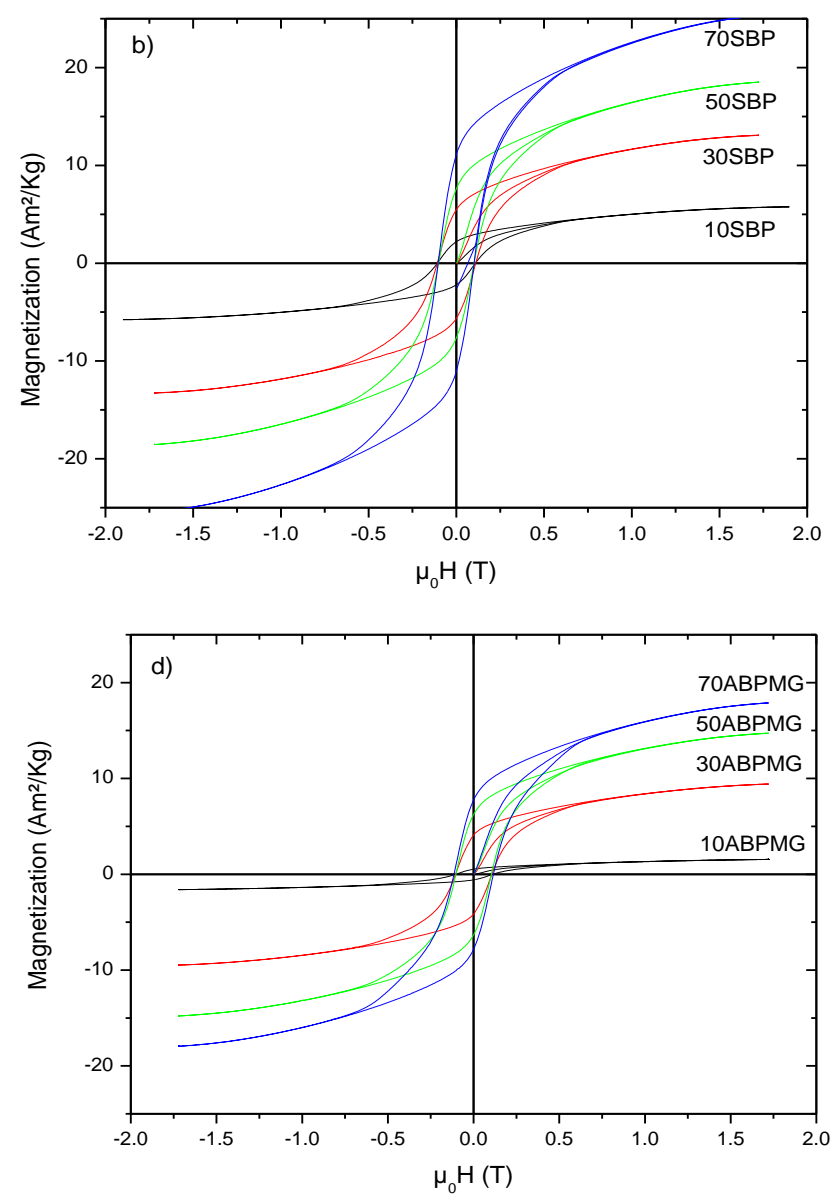
Fig. 13.

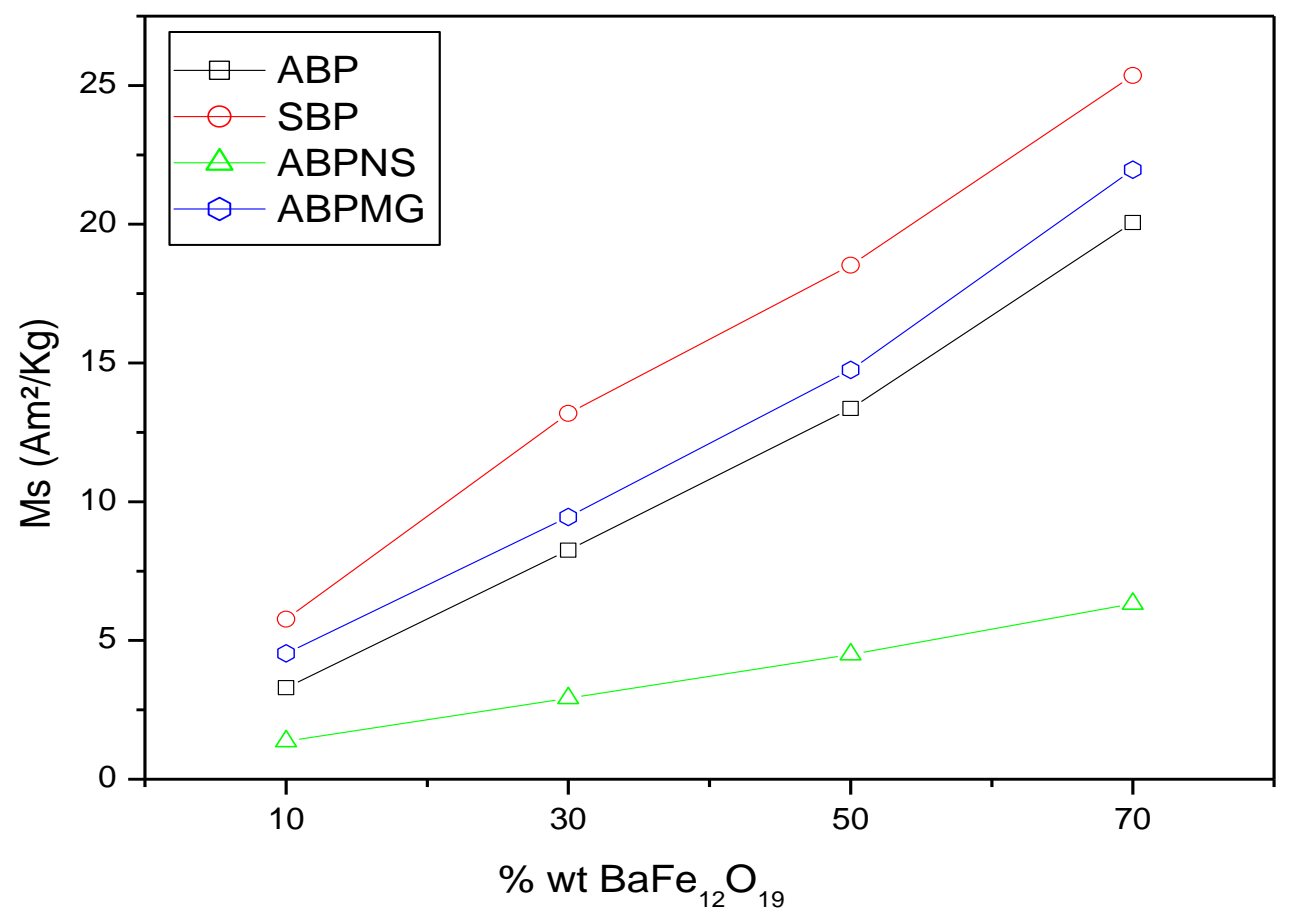


Fig. 14.

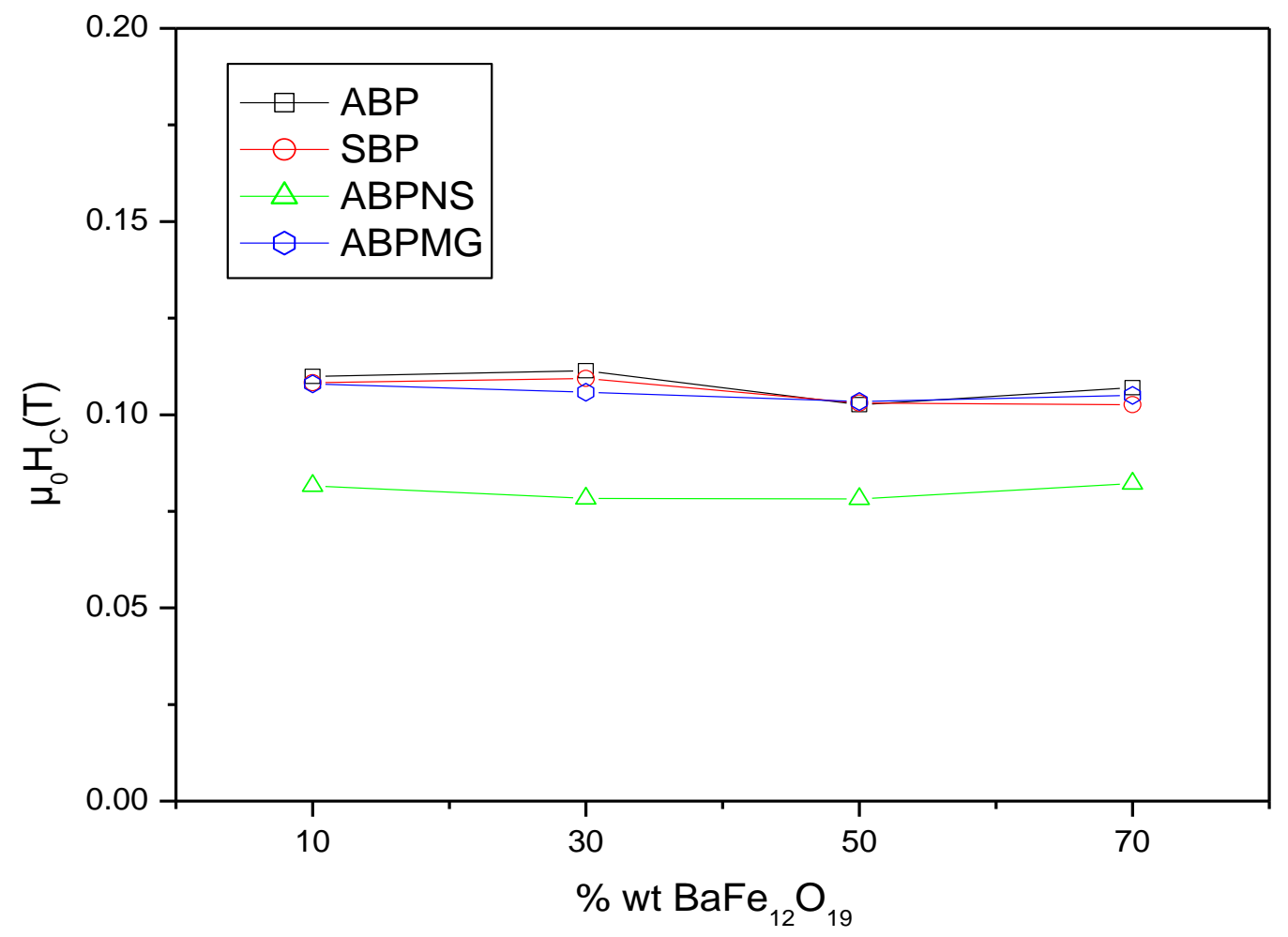

